\title{
Expression of cysteine proteinases and cystatins in parasites and use of cysteine proteinase inhibitors in parasitic diseases. Part III: Protozoa (3): Kinetoplastids
}

Article

\author{
Sherif M Abaza
}

Medical Parasitology Department, Faculty of Medicine, Suez Canal University, Ismailia, Egypt

\begin{abstract}
Kinetoplastids, or trypanosomatids are flagellate protozoa characterized by the presence of a kinetoplast composed of a DNA network of circular molecules, localized near the basal body. Cysteine proteinases (CPs) have attracted considerable attention in pathogenic trypanosomatids over the last two decades due to their essential roles in parasite' growth, transformation, proliferation, migration and invasion, as well as immunomodulation of host immune system. Because CPs are essential virulence factors during all stages of the infection process, a number of new strategies to obstruct trypanosomatid biological processes have emerged; one of them is focused on using $\mathrm{CP}$ inhibitors (CPIs). The objective of the present review is to highlight the molecular characterization and functions of CPs in pathogenic trypanosomatids. Sufficient knowledge aided with bioinformatics analysis can lead to efficient development of diagnostic and biogenetic markers, drug targets (potent CPIs), and vaccine candidates. The role of the unusual endogenous CPI (CYS) in trypanosomatids will also be discussed.
\end{abstract}

Keywords: brucipain, calpain, cathepsin-like, chagasin, cruzipain, drug target, trypanosomatids, vaccine candidate.

Received: 23 November, 2019, Accepted: 25 November, 2019.

Corresponding Author: Tel.: +20 1005243428, E-mail: smabaza@hotmail.com.

Print ISSN: 1687-7942, Online ISSN: 2090-2646, Vol. 12, No. 3, December, 2019.

Abbreviations: ATG: Autophagy-related gene; CALP: Calpain; CATH: Cathepsin; CPB2.8DCTE: CPB2.8 copy without extension of its C-terminus; CL: Cutaneous leishmaniasis; CP: Cysteine proteinase; CPI: Cysteine proteinase inhibitor; CRZ: Cruzain; CTE: C-terminus extension; CYS: Cystatin; E-64: A broad spectrum CPI; HTS: High throughput screening; MCA: Metacaspase; PCD: Programmed cell death; SAR: Structural activity relation; VL: Visceral leishmaniasis.

Cysteine proteinases (CPs) in pathogenic trypanosomatids are virulence factors, and promising targets for development of novel drugs and vaccine candidates ${ }^{[1-4]}$. The most frequently studied CPs belong to cathepsins (CATH; clan CA, family C1), calpains (CALP; clan CA, family C2) and metacaspases (MCA, clan CD, family C14). In all trypanosomatids, CATHlike CPs possess a long C-terminus extension (CTE). Cathepsin-like CPs with their CTE and their crucial roles as virulence factors and capability to elicit host immune response, as well as their applications as drug targets, diagnostic or biogenetic biomarkers and vaccine candidates will be individually discussed later.

Trypanosomatid CALPs, similar to mammalian CALPs-calcium-dependent CPs, are involved in a variety of cellular events, e.g., signal transduction, cytoskeleton remodeling, and environmentallyregulated processes ${ }^{[5]}$. On molecular basis, genes encoding CALPs in pathogenic trypanosomatids ware categorized into five groups. Members of group 3 are termed small kinetoplastid CALP-related proteins (SKCRPs) that contain only the exclusive $\mathrm{N}$-terminus (the proteolytic domain). Ten, nine, and six SKRCPs were identified in L. major, T. cruzi, and T. brucei, respectively ${ }^{[6]}$. On the other hand, Brazilian reviewers claimed that comparative studies between drug resistant and sensitive isolates of pathogenic trypanosomatids showed up-regulation of virulencerelated genes in infective parasite stages. As genes encoding CALPs were upregulated, the reviewers recommended complete genome sequences of pathogenic trypanosomatids to identify potential chemotherapeutic agents ${ }^{[7]}$.

Programmed cell death (PCD) machinery pathway includes apoptosis and autophagy. The latter is involved in cell turnover through removal of damaged cells and homeostasis regulation for cellular crucial processes; growth and differentiation. Identification of autophagy-related genes (ATGs) showed participation of several proteins in PCD pathway ${ }^{[8]}$. In contrast to mammalian caspases, MCAs were shown to contribute in autophagy, not apoptosis ${ }^{[9]}$. Two other differences were observed; MCAs cleave their substrates after arginine and lysine residues in the $\mathrm{P} 1$ position, instead of asparagine in caspases. Second is their activation by calcium ${ }^{[10]}$. Recently, MennaBarreto $^{[11]}$ reviewed trypanosomatid PCD machinery pathway and presented a figure for the distribution of apoptotic or autophagic molecules in Leishmania spp., T. cruzi and T. brucei. Proteins associated with apoptosis (MCAs) were mainly demonstrated in trypanosomes, followed by $L$. donovani and $L$. infantum, and vice versa for proteins contributed in autophagy (ATGs) that were mainly assessed in $L$. major, followed by trypanosomes ${ }^{[11]}$. 
When the crystal structure of C11 peptidase was characterized, British investigators succeeded to identify an important gene encoding protein termed as Puf nine target 1 (PNT1) in trypanosomatids. The investigators observed that PNT1 showed potential proteolytic activity similar to those of CPs, and was immunolocalized to the kinetoplast DNA. Demonstrated by gene knockout studies, PNT1 proteolytic activity was required for kinetoplast maintenance. Phylogenetic analysis revealed that PNT1 was structurally divergent from those identified in coccidian protozoa ${ }^{[12]}$.

Chagasin, the endogenous inhibitor of CPs (CYS), was described in T. cruzi ${ }^{[13]}$, and later in L. mexicana, L. major and T. brucei ${ }^{[14]}$. Functional homology between the identified chagasin suggested a common evolutionary origin. Several evidences were observed suggesting that inhibition of host CPs was the essential role of chagasin ${ }^{[14]}$. Later, an American study identified the crystal structure of chagasin in a complex with its CP. They found that it had unique variant of an immunoglobulin fold with homology to human $\operatorname{CD} 8 \alpha$. Chagasin possesses three binding loops (BC, DE, and FG) to fit in the active site groove of human CATHs obstructing substrate binding. Based on the obtained results, the investigators attributed differences in their functional requirements to the highly homologous binding loops evolved in chagasin to be used as scaffold for protein binding ${ }^{[15]}$. Due to lack of a significant identity with CYS classes, it is assigned in a recent classification as clan IX, family I42 $2^{[16]}$.

\section{Leishmania spp.}

Silva-Almeida et $a .^{[17]}$ attributed variable clinical presentations in leishmaniasis to the high diversity of proteinases, as L. braziliensis alone has 97 metallo-, 44 cysteine, and 23 serine proteinases. The reviewers claimed that beside parasite survival and virulence, CPs influenced host immune response via: 1) expression of Th1-associated cytokines with production of ILs 4,5 and 10 , as well as IFN- $\gamma$ with inhibition of IL12 production; 2) association with cleavage of the major histocompatibility complex (MHC) class II gene products; 3 ) stimulation of $\mathrm{CD}^{+}$T-lymphocytes; and 4) contribution in parasite resistance against killing by macrophages through immunomodulation ${ }^{[17]}$. Later, the same investigators utilized genomic analysis of four Leishmania spp. and observed great diversity of genes encoding proteinases. The investigators observed that cysteine and serine proteases, with close percentages, predominate in all analyzed species except L. braziliensis, where metalloproteases were the predominant. The investigators concluded that the observed great diversity in Leishmania spp. are related to establishment of the infection in their hosts; either the vector gut or the mammalian immune system ${ }^{[18]}$.

In order to survive host antimicrobial activities, intracellular amastigotes have to develop several highly successful strategies including antigen presentation, nitric oxide (NO), oxygen radical generation and cytokine production. Host immunoevasion is necessary for amastigotes to divide within infected macrophages, and propagate the disease within the host. The molecular mechanisms were discussed and the reviewers concluded that it is certain that significant differences would exist in the mechanisms of host cell manipulation, and this was attributed to the diversity of Leishmania spp. ${ }^{[19]}$.

\section{Cysteine proteinases (CPs)}

Cathepsins: Leishmania CATHs include two CATHs L-like (CPA and CPB) and one CATH B-like (CPC). Other terms for CPA and CPB were used in some publications as cys 1 and cys2, respectively. British scientists characterized genes encoding $\mathrm{CPB}$ in $L$. mexicana. Its expression level was developmentally regulated, being high in amastigotes, low in metacyclic forms and undetectable in promastigotes ${ }^{[20]}$. A single copy of each gene encoding CPA and CPC was identified ${ }^{[21]}$, and the multi-copy CPB gene of L. mexicana was located in a single locus of 19 copies arranged in a tandem repeat ${ }^{[22]}$. Only 5 and 8 copies were detected in L. chagasi $^{[23]}$, and L. major $^{[24]}$, respectively.

Using gene sequencing and analysis of $c p b$ multicopy gene of L. mexicana, three different nucleotide sequences of their repeat units were observed. The copy (cpb2), expressed in metacyclic forms, contains four insertions with a $3^{\prime}$-untranslated region (3UTR). The last 16 copies (cpb3-cpb18), expressed in amastigotes, possessed a CTE extension. A copy in between $c p b 2$ and $c p b 3$, termed $c p b 2.8$, possessed the CTE and 3-UTR. Expression in metacyclic forms occurred with $c p b 2$ or $c p b 2.8$ with its 3-UTR. In amastigotes, expression occurred with $c p b 3-c p b 18$ or $c p b 2$ with a CTE of $c p b 2.8^{[22]}$. Later, gene sequencing of $2 c p b$ copies: $c p b E$ and $c p b F$ revealed that the first was specific to $L$. infantum, while the latter to L. donovani, and both copies were different in length and sequence. Phylogenetic studies were conducted in France to compare both copies with those reported in species of $L$. mexicana and L. donovani complexes. Results pointed to three issues: 1 ) both copies shared a sequence pattern specific to $L$. donovani complex; 2) different levels of polymorphism between $L$. infantum and $L$. donovani; and 3) L. infantum dermotropic strains showed more polymorphism than viscerotropic strains ${ }^{[25]}$.

It was reported that CATH B-like and L-like CPs in Leishmania spp. differ in their structures with different proteolytic mechanisms. When the substrate binds with CATH L-like, it spans the entire channel between the two CP domains, leading to proteolytic activity. Cathepsin B-like has an additional loop that restricts substrate binding under low $\mathrm{pH}$, where at high $\mathrm{pH}$, the loop allows for proteolytic activity ${ }^{[26]}$. Recently, surface plasmon resonance assay was used to track the fate of the CTE of L. amazonensis CPB; whether it remained as CTE or was expressed as CPB prodomain in cultured 
promastigotes and amastigotes. Using CTE antibodies and a broad spectrum CPI (E-64), results revealed that both stages extracellularly released CTE, while only promastigotes released CTE as CPB prodomain ${ }^{[27]}$.

\section{Leishmania CATHs and clinical presentations}

Variable clinical presentations in leishmaniasis were attributed to differences in CPs expression levels and specificities. While L. mexicana usually causes chronic lesions, L. major often causes selflimited lesions. When L. mexicana CPB was transfected into mutant $L$. major, diminished Th1 response and elevated Th2 response with high IFN- $\gamma$ production was observed. Hence, it was concluded that gene expression levels or its substrate specificity are different between both species ${ }^{[28]}$. Sequencing of the gene encoding $L$. amazonensis CPA (Lmacys1) showed high similarity with CPB of L. chagasi (Ldccys2) ${ }^{[29]}$. Similar results were obtained when Canadian investigators observed significant sequence identity in $L$. chagasi CPB with $L$. mexicana $\mathrm{CPA}$, but with lower sequence identity with L. mexicana CPB. Accordingly, the differences in gene sequencing and CPs expression between L. mexicana and L. donovani complexes were confirmed ${ }^{[30]}$.

Several differences within species of L. mexicana complex were also observed in megasomes. The latter are large lysosome-like structures in amastigotes linked to CPs expressions. Brazilian investigators immunolocalized CPs in amastigotes of three Leishmania spp. They observed variations in megasome size and number either in cultured amastigotes or those obtained from infected animals. Higher volume of megasomes was observed in lesion-derived amastigotes compared with cultured amastigotes in $L$. amazonensis and L. mexicana, with the latter 2-3 times higher. In contrast, cultured L. pifanoi amastigotes showed a small megasomes volume with low CPs activity and inability to cause lesions in animal models. Accordingly, significant differences of structural organization of CPs distribution within the L. mexicana complex was concluded ${ }^{[31]}$. Similar conclusion was obtained when a study conducted in Peru observed $70 \%$ sequence identity between L. braziliensis and L. mexicana CPBs, but with a significant difference in substrate preference. A CPI with proline at P1 showed high affinity to L. braziliensis $\mathrm{CPB}$, while L. mexicana CPB preferred substrates with phenylalanine, leucine, and asparagine at P1. Accordingly, the investigators suggested amino acid modifications outside the core of the active site cleft for substrate preference ${ }^{[32]}$.

\section{Leishmania CATHs for survival and virulence}

A comparative study of proteinases in virulent and avirulent L. amazonensis promastigotes showed significant expression of $\mathrm{CP}$ activities in virulent promastigotes ${ }^{[33]}$. A postulated mechanism for the role of Leishmania CPs to enhance parasite survival in infected macrophages was hypothesized. Significant increased level of activated tumor growth factor- $\beta$
(TGF- $\beta$ ) in L. chagasi-infected mice was observed, and was inhibited by addition of a specific CPB inhibitor ${ }^{[34]}$. Brazilian investigators observed that CPs had a key role in growth, viability, and pathogenicity of L. tropica, with close similarity to L. major rather than L. mexicana. However, pathogenicity of L. tropica amastigotes in mice was reduced by CPI treatment with similar rate as observed in both L. major and L. mexicana ${ }^{[35]}$.

Importance of $\mathrm{CPB}$ as a major virulence factor for $L$. mexicana complex species was investigated. It was documented that the multiple copies of $c p b$ gene express CPB with complementary functions for the sake of survival and virulence of promastigotes and intracellular amastigotes ${ }^{[36-38]}$. Later, Brazilian investigators analyzed profiles of the proteolytic activities of cellular and extracellular CPB and the Leishmania metalloprotease virulence factor (gp63). They investigated both virulence factors in isolated virulent and a cultured avirulent $L$. braziliensis strains. Expression of both proteases was exclusively detected in the virulent strain, and was sharply decreased after several in vitro subcultures. Growth arrest and virulence decrease of the virulent strain were observed on E-64 addition ${ }^{[39]}$. Similar results were obtained when another group of Brazilian investigators verified that CPB expression was modified during in vitro subcultures of $L$. braziliensis promastigotes ${ }^{[40]}$. In 2013, proteomic analysis of $L$. donovani CPB mutant and wild type (WT) identified several modulated proteins. Because the majority of them were lysosomal secreted proteins; the investigators concluded an essential virulence role of CPB through their effect on Leishmania secreted proteins ${ }^{[41]}$. Capability of $\mathrm{CPB}$ to modulate levels of gp63 in Leishmania species was shown. Minimal expression of gp63 in CPB-deficient parasites was sufficient to restore virulence to WT levels $^{[42]}$. On the other hand, the role of the CTE in Leishmania virulence was also investigated. The role of L. pifanoi CPB-CTE (Lpcys2 CTE) in early infection was demonstrated. Beside its lysosomal localization, Lpcys2 CTE was shifted towards the flagellar pocket of cultured amastigotes during early stage of macrophage infection $^{[43]}$.

There is evidence that CPC is also considered an important virulence factor in Leishmania spp. due to its partial contribution in increasing L. chagasi capacity to induce TGF- $\beta$ expression in human cell cultures ${ }^{[44]}$. Also, assays based on gene suppression showed that L. infantum CPA acted as a virulence factor. Mutant clones significantly reduced virulence in vitro and in vivo. However, re-expression of one LiCPA allele was sufficient to retrain virulence in human macrophages in vitro, but not in vivo. The investigators confirmed that CPA had an essential role for the host-parasite interaction, and not for promastigotes replication ${ }^{[45]}$. In contrast, another study conducted in Ethiopia observed that expression of CPA and CPB in L. aethiopica was during the stationary phase of development ${ }^{[46]}$. 


\section{Leishmania CATHs and host immune response}

One of the factors influencing outcome of Leishmania infection is the balance between Th1 response antagonizing infection, and Th2 response in the favor of parasite survival. Leishmania CPB have an essential role in the differentiation of functional $\mathrm{CD}^{+} \mathrm{T}$ cells. Using a specific CATH B inhibitor, Maekawa et al. ${ }^{[47]}$ observed modulation of host immune response from $\mathrm{Th} 2$ to Th1 type in susceptible BALB/c mice infected with $L$. major. Also, it was suggested that Leishmania $\mathrm{CPB}$ and mammalian CATH L had the same function as antigenprocessing proteases, but in a different manner. While Leishmania $\mathrm{CPB}$ modulated host immune response by Th2 upregulation and/or Th1 suppression, the latter processed Leishmania antigens only to Th1 response ${ }^{[48]}$. Later, the immunogenic properties of L. infantum CPA and $\mathrm{CPB}$ mature domains were investigated against sera from active and recovered cases of visceral leishmaniasis (VL). Intensive recognition was detected in both sera with higher recognition toward $\mathrm{CPB}^{[49]}$.

Several mechanisms were postulated for CPs modulation of host immune response. In mice infected with mutant L. mexicana (deleted $c p b$ multi-copy gene), several hypotheses were postulated for suppression of Th1 immune response; either indirectly or directly. The indirect mechanism involved inhibition of antigen presentation cells via CP-mediated degradation of MHC class II molecules and inhibition of $\mathrm{T}$ cell proliferation. Direct mechanisms involved altering Th1 pathways or their crucial transcription factors. Accordingly, the investigators suggested utilizing CPB specific inhibitors for treatment of chronic leishmaniasis ${ }^{[28]}$. Similar results were obtained when the investigators inserted only $c p b 2.8$ or $c p b 2$ gene into $c p b$-mutant $L$. mexicana. Results revealed failure to restore either Th2 response or virulence. Re-expression of $c p b$ gene significantly increased lesion growth accompanied by Th2 response with increased production of IL-4, IgG1 and $\operatorname{IgE}^{[38]}$. In L. mexicana, two other mechanisms were postulated for CPB down regulation of protective Th1 immune response; IFN- $\gamma$ production and inhibition of IL-12 production by infected macrophages ${ }^{[50]}$. Another reported mechanism of Leishmania CPs was the proteolytic activity of kininogens liberating kinins. The latter were recognized as signals alerting the innate immune system. The investigators demonstrated that both L. donovani and L. chagasi activated kinin pathway to enhance microvascular responses; i.e. modulation of innate immunity in VL. Interestingly, kinin pathway was inhibited using irreversible CPIs ${ }^{[51]}$. Later, L. mexicana CPB was reported to have a crucial role in alteration of macrophage signaling pathways and inactivation of transcription factors leading to nuclear failure to respond to IFN- $\gamma$ stimulation ${ }^{[52]}$.

As CTE-CPB was reported to influence the interaction of parasites with the host immune system, the investigators hypothesized that the CTE is hydrolyzed when CPB is processed to its mature form and was secreted into the extracellular environment $\mathrm{t}^{[23]}$, and inside host cells ${ }^{[53]}$ altering host immune system. In murine leishmaniasis models, BALB/c mice are highly susceptible, while CBA mice are mildly resistant, and this was attributed to inefficient Th1 response rather than a dominant Th2 response ${ }^{[54]}$. The protective potentiality of the CTE of L. infantum CPA was investigated in BALB/c mice. The investigators observed increased levels of IgG2a and IL-5, and concluded that recombinant CTECPA was immunogenic and displayed both Th1 and Th2 immune responses in experimental $\mathrm{VL}^{[55]}$.

To elucidate the molecular mechanism of CTE in Th1/Th2 immunomodulation for the favor of parasite survival, three studies were conducted in two mice models. In the first study, the investigators conducted in silico mapping to predict three peptides (epitopes) in the CTE of L. amazonensis CPB that were suggested to bind with MHC molecules. Results revealed more intense Th1 response only in infected CBA mice, but a Th2 response was observed in both models ${ }^{[56]}$. This suggested that inefficient Th1 response contributed to increased susceptibility of BALB/c mice. In the second study, the investigators demonstrated diversity of stimuli by the selected peptides on Th1/Th2 response for the best favor of parasite survival. In silico simulation studies showed that there were essential amino acid residues in one of them (PI) to help binding with the MHC cleft. Molecular docking studies demonstrated confirmatory evidence for the relation between PI capacity and expression of specific cytokines for Th1/ Th2 balance. The distinct immunomodulatory effects on cytokines (Th1/Th2 balance) was attributed to the interaction between MHC classes and PI in the CTE ${ }^{[57]}$. Analyzing gene expression of L. amazonensis $\mathrm{CPB}$ and $\mathrm{CPC}$ as well as host gene expression related to $\mathrm{T}$ cell response balance (Th1/Th2), namely MHC classes I and II was conducted in the third study. Expression of CPB predominated over that of CBC in both mice models, while MHC classes I and II had higher expression levels in CBA and BALB/c mice, respectively ${ }^{[58]}$.

\section{Leishmania CATHs and autophagy}

Leishmania CPA and CPB proved to be essential for autophagy, an essential process during differentiation and transformation (promastigotes $\leftrightarrow$ amastigotes). Autophagosomes were much more demonstrated during promastigotes conversion to amastigotes than the other transformation form. Deletion of both genes inhibited autophagy pathway, and prevented metacyclogenesis both in vitro (macrophages) and in vivo (mice) ${ }^{[59]}$. In addition, an essential role played by CPC was reported in Leishmania PCD machinery. As previously reported, the strategy "protozoa commit suicide to survive" was suggested ${ }^{[60]}$. That is to say "dead promastigotes enable the intracellular survival of the viable amastigotes influencing parasite virulence". In their study, El-Fadili et al. ${ }^{[61]}$ identified Leishmania CPC as an efficient substrate of a pan-caspase inhibitor. The investigators provided evidence for induction of PCD by 
various stress conditions. The induced high expression of Leishmania CPC activates PCD machinery pathways controlling the density of Leishmania population in its host $^{[61]}$.

\section{Leishmania CATHs as diagnostic markers}

A group of Belgium scientists utilized Leishmania CATHs for the genetic characterization of Leishmania species. Application of restriction fragment-length polymorphism (RFLP) of PCR-amplified sequences of the multi-copy gene encoding $\mathrm{CPB}$, characterized 15 references strains of $L$. donovani complex. The investigators validated their protocol because PCRRFLP allowed direct characterization of Leishmania species in human tissue samples ${ }^{[62]}$. Other Belgium investigators developed a rapid PCR technique to differentiate between five Leishmania spp. and it was validated in cultured isolates ${ }^{[63]}$. One year later, a third Belgium publication reported use of three nuclear loci encoding three markers; g63, CPB, and hydrophilic acylated surface protein B markers to genotype thirty-four $L$. donovani clinical isolates obtained from Nepal. Results showed eight genotypes using combined markers. The investigators recommended further studies to utilize these markers to study the epidemiological factors involved in parasite populations, distinguish relapses from re-infection, and monitor strains spread ${ }^{[64]}$. Gene encoding CPB was also investigated to design primers for routine diagnosis of leishmaniasis caused by L. aethiopica. The investigators claimed that these primers were able to differentiate between L. aethiopica from other Leishmania spp. ${ }^{[65]}$.

Tunisian investigators published two articles in 2013 utilizing $c p b$ gene. The first reported a RFLP-PCR with selected primers to differentiate between several Tunisian Leishmania isolates. Utilizing phylogenetic analysis, the primers enabled the investigators to identify a new Tunisian species, L. killicki which was an evolved isolate from the L. donovani complex originated from East Africa ${ }^{[66]}$. In the second report, they used loop mediated isothermal amplification (LAMP) to amplify six primers targeting $L$. infantum $c p b$ gene. No cross reaction was observed with other Leishmania spp. and T. cruzi or human genomic DNA. Although moderate sensitivity and high specificity were observed, LAMP showed the highest kappa value ( 0.34 fair agreement). Moreover, relative stability of LAMP reagents suited its use in field blood samples ${ }^{[67]}$.

Three publications were issued by a group of Brazilian scientists ${ }^{[68-70]}$ investigating recombinant $L$. chagasi CPA (rLdccys1) as a serodiagnostic marker in VL caused by L. chagasi in Latin America. It was utilized to assess cellular immune responses in naturally VLinfected humans and dogs. The investigators detected elevated levels of IFN- $\gamma$ only in asymptomatic subjects, or associated with ILs 4 and 10 in symptomatic subjects $^{[68]}$. Also, it showed high sensitivity rates for detection of specific antibodies in sera obtained from patients with active VL. Results revealed 98\% and $99 \%$ sensitivity to lysates of promastigote and amastigote, respectively, with no cross reactions with sera of Chagas's disease patients ${ }^{[69]}$. Later, it was used to diagnose canine VL and to discriminate between clinical and subclinical infections. Results revealed no cross-reactivity with sera obtained from patients with Chagas' disease, however little reactivity was detected with sera from dogs with babesiosis. Delayed type hypersensitivity (intradermal response) was also determined, and the results revealed that all asymptomatic dogs showed positive results with a peak at $48 \mathrm{~h}$. In contrast, no significant response was observed in the symptomatic $\operatorname{dog} \mathrm{s}^{[70]}$.

\section{Leishmania CATHs as vaccine candidates}

L. chagasi CPA (Ldccys1) in DNA construct and its recombinant form were utilized to investigate their potentiality to produce protective responses in BALB/c mice challenged with $L$. chagasi amastigotes. Mice immunized by both protocols together induced significant secretion of IFN- $\gamma$, NO and IgG $2 \mathrm{a}$ antibodies suggesting a predominant Th1 response ${ }^{[71]}$.

Due to its significant induction of Th2 immune response, British investigators suggested using $L$. mexicana cpb2.8 gene as a potential vaccine candidate if administered with a suitable adjuvant ${ }^{[72]}$. Colombian investigators also succeeded to achieve significant protection against $L$. mexicana challenge infection utilizing $c p b$-mutant attenuated live promastigotes. Significant lower levels of Th2-associated cytokines (IL-10 and TGF- $\beta$ ) were observed in comparison to WT infection ${ }^{[73]}$. Later, six Leishmania antigens were evaluated as vaccine candidates for VL. To measure vaccine validity, the investigators found that out of the six tested cytokines, only IFN $-\gamma$ differentiated cured VL patients from non-exposed individuals. The most immunogenic and protective antigen was CPB followed by sterol 24-c-methyltransferase. The investigators recommended further studies for clinical development of a valid vaccine against $\mathrm{VL}^{[74]}$.

Utilizing both CPA and CPB as a vaccine candidate was reported in several publications. Iranian investigators utilized recombinant $\mathrm{CPA}$ and $\mathrm{CPB}$ to control VL in dogs. Results revealed that almost all vaccinated dogs showed strong delayed type hypersensitivity responses compared to control $\operatorname{dogs}^{[75]}$. Two delivery systems (electroporation and nanotechnology) of a vaccine composed of $L$. donovani A2 antigen with $L$. infantum CPA and CPB without its CTE (CPB2.8 $\triangle \mathrm{CTE}$ ) were evaluated. Both delivery systems induced protective immunity associated with a strong Th1 immune response, as well as high levels of IgG antibodies and NO production. Histopathological studies and parasite burden showed similar protection levels ${ }^{[76]}$. Nanotechnology was also utilized in another study to develop a protective vaccine against CL. Recombinant L. major CPA and CPB were conjugated 
with PLGA nanoparticles to enhance immune response in BALB/c mice. After L. major challenge infection, the investigators concluded that vaccination using CPs combined with nanoparticles produced the most significant protection ${ }^{[77]}$. Recently, outbred dogs were vaccinated with nonpathogenic $L$. tarentolae combined with $L$. donovani A2 antigen, CPA and CPB2.8DCTE against $L$. infantum challenge infection. Vaccinated dogs showed strong delayed type hypersensitivity associated with low bone marrow parasite burden. After challenge infection, highest percentage of subclinical infection and the lowest percentage of symptomatic stage were observed. Because dog is the major reservoir host for $\mathrm{VL}$, vaccination against canine leishmaniasis was recommended as a strategy to control $\mathrm{VL}^{[78]}$.

Applying $L$. infantum $\mathrm{CPC}$ as a vaccine candidate was also investigated. Significant high ratio of IgG2a/ IgG1 associated with NO and IFN- $\gamma$ production, were observed in the vaccinated mice compared to the control group ${ }^{[79]}$. Immuno-informatics was utilized to predict three specific immunogenic peptides in $L$. donovani CPC. The predicted peptides (P 1-3) showed low sequence similarity with Homo sapiens, suggesting high potentiality and specificity to elicit human T-cell immune response. Interestingly, these predicted peptides were highly conserved in L. major, L. infantum and $L$. chagasi. The investigators selected two peptides (P1 and P3) because they showed strong binding affinity with the HLA A02 allele in vitro. Significant potentiality of individual P1 or P3 to generate protective immune response $\left(\mathrm{CD}^{+}{ }^{+} \mathrm{T}\right.$-cell proliferation) was observed in treated VL patients compared to healthy controls. Development of DNA vaccine against VL employing combined P1 and P3 was recommended ${ }^{[80]}$.

\section{Calpains (CALPs)}

Employing whole-genome analysis, a total of 27 CALP-like proteins were characterized in L. major ${ }^{[6]}$. Using anti-CALP antibodies, CALP-like molecules on the cell surface of L. amazonensis were localized. The investigators observed growth arrest on addition of a specific CALP inhibitor ${ }^{[81]}$. Caldonopain, a CALP-like proteinase, was identified in $L$. donovani cytosolic fraction. Because it showed a calcium-dependent proteolytic activity, caldonopain was suggested as novel drug target against $\mathrm{VL}^{[82]}$.

Utilizing gene expression microarray technology, the investigators observed a double-fold higher expression of five proteins in L. donovani isolated from patients with post kala-azar dermal leishmaniasis in comparison with those isolated from VL patients. Among them, a short protein with significant homology to trypanosomatids CALPs, was identified. The investigators suggested that $L$. donovani CALP might contribute to drug resistance in VL ${ }^{[83]}$. Similarly, a proteomic analysis between drug-resistant and sensitive $L$. donovani strains isolated from patients with VL was conducted. In the resistant strain, down regulation of the gene encoding small kinetoplastid calpain-related protein (SKCRP14.1) was observed. It was concluded that $L$. donovani CALP increases the parasite susceptibility ${ }^{[84]}$. To identify biomarkers for miltefosine resistance in VL patients, a recent study used cultured splenic aspirates from two groups of VL patients; one successfully treated with miltefosine and another that had relapsed after initial cure. The investigators only identified a CALP-like protein with significant over expression in relapsed patients. It was concluded that Leishmania CALP can be used as a potential biomarker of miltefosine resistance ${ }^{[85]}$.

\section{Metacaspases (MCAs)}

In leishmaniasis, reactive oxygen species, including $\mathrm{H}_{2} \mathrm{O}_{2}$, are produced by anti-leishmanial drugs or infected macrophages to participate in killing intracellular Leishmania. A group of researchers found that pre-treatment of L. donovani promastigotes with a specific CPI reduced the number of apoptotic cells, and prevented DNA fragmentation. Role of Leishmania MCA (clan CD, family C14) in activation of caspase-like proteins leading to PCD was suggested ${ }^{[86]}$ Similar results were obtained using E-64, suggesting involvement of Leishmania MCA in PCD, similar to intracellular protozoa ${ }^{[87]}$.

In 2007, a single mca gene was identified in $L$. major. The investigators observed that the proteolytic activity of $L m M C A$ was auto-processed, and it preferred substrates with arginine in the $\mathrm{P} 1$ position, but not caspase substrates $^{[88]}$. To elucidate MCA molecular role involved in PCD, genomic sequence analysis revealed three main domains; N-terminus; catalytic domain and proline rich C-terminus ${ }^{[89]}$. To predict the relevant cleavage sites for auto-processing of $L m M C A$ catalytic domain, Swiss investigators suggested R63, R315 at the $\mathrm{N}$-terminus, and R298 at the C-terminus domains ${ }^{[90]}$. From the previous studies, it was concluded that biochemical characterization and identification of LmMCA natural substrates ${ }^{[89]}$ and/or identification of relevant cleavage sites of its auto-processing ${ }^{[90]}$ would help in development of novel drugs against leishmaniasis.

In contrast to L. major and similar to L. infantum, two genes encoding MCAs were cloned and characterized in $L$. donovani ( $L d \mathrm{MCA} 1$ and $L d \mathrm{MCA} 2$ ). Their sequence showed $98 \%$ homology and possessed a characteristic C-terminus proline-rich domain. The investigators observed mRNA transcripts in promastigotes and axenic amastigotes, with significant more $L d \mathrm{MC} 1$ transcripts in axenic amastigotes. Pretreatment with $\mathrm{H}_{2} \mathrm{O}_{2}$ induced $L d M A C s$ overexpression ${ }^{[91]}$. Also, another study revealed MCAs over-expression of cultured L. infantum promastigotes $6 \mathrm{~h}$ after treatment with miltefosine. The investigators suggested that MCAs initiated signaling for apoptosis pathway ${ }^{[92]}$. The roles of $L d \mathrm{MC1}$ and heat shock protein 70 (HSP70) in PCD of $L$. donovani were identified in gene knockdown 
studies. Individual gene knockdown showed marked cell death, while simultaneous knockdown led to maximum damage. Both L. donovani MC1 and HSP70 were suggested as drug targets ${ }^{[93]}$. For L. mexicana, British investigators generated null mutant clones of L. mexicana promastigotes and amastigotes (deletion of $m c a$ gene), and they observed their differentiation in vitro and virulence in vivo, respectively. It was concluded that $L m$ MCA was only an essential survival factor for amastigotes replication inside the mammalian host ${ }^{[94]}$.

\section{Other understudied CPs}

Leishmania spp. possess two ATG4 CPs (ATG4.1 and ATG4.2) for their autophagy process that is essential for cell differentiation. However, it was demonstrated that ATG4.2 expression, not ATG4.1, increased parasite virulence through its essential role in autophagy ${ }^{[95]}$. Otubain (clan CA, family C65), a deubiquitinating enzyme (DUB) with an essential role in regulating several eukaryotic processes, was recently characterized in $L$. infantum (Otu $L i)^{[96]}$. It is worth mentioning that ubiquitination is a process in which an ubiquitin molecule (Ub) covalently binds to a substrate to regulate a specific signaling pathway ${ }^{[97]}$. Localization of $L$. infantum otubain cytoplasm in promastigotes indicated its essential role in pro-inflammatory response of stimulated murine macrophages ${ }^{[96]}$.

\section{Cysteine proteinase inhibitors (CPIs)}

Several studies were conducted investigating peptide proteinase inhibitors in treatment of leishmaniasis. A CATH B inhibitor, RT-01 (a synthetic organotellurane) inhibited the growth of cultured L. amazonensis amastigotes and promastigotes. Significant delay in cutaneous lesions development and decreased parasite intensity were observed after intra-lesional administration for one month ${ }^{[39]}$. Also for treatment of CL, subcutaneous injections of DPPE 1.2, a metalloproteinase inhibitor, showed significant inhibitory activity against L. amazonensis CPB. Its application in experimentally infected mice for one month significantly decreased lesion size and produced $97 \%$ reduction of parasite burden ${ }^{[98]}$. In another study, one of the organotelluranes, RF07, was investigated for treatment of VL. Intraperitoneal injection for one month produced almost complete reduction in the parasite burden ${ }^{[99]}$. Recently, derivatives of dipeptidyl nitriles, selective inhibitors of human dipeptidyl aminopeptidase 1 (DPAP1), were investigated. Significant growth inhibition of in vitro cultured promastigotes of $L$. amazonensis and $L$. infantum was observed. Unfortunately, DPAP inhibitors caused cytotoxic effects on infected macrophages that impaired further analysis of the amastigote infection ${ }^{[100]}$.

Due to the significant potentiality of vinyl sulfones as leishmanial CPIs, several non-peptide and peptidomimetic inhibitors were investigated. Three studies were conducted by a group of scientists from Germany and Venezuela utilizing synthetic aziridine-2,3-dicarboxylates. It was demonstrated that compounds $13 \mathrm{~b}$ and $13 \mathrm{e}$ impaired in vitro promastigote growth, and decreased macrophages infection rate. However, when compared to amphotericin B in vivo, both compounds exhibited less potency suggesting their direct inhibitory activity against Leishmania $\mathrm{CPB}^{[101]}$. Apoptotic markers were observed when both compounds were investigated targeting Leishmania CPC. Unfortunately, they caused inhibition of host CATH L ${ }^{[102]}$. To discriminate between host and parasite CPs, more selective inhibitors were synthesized based on both compounds. Compound s9 showed selective inhibitory potency against L. major CPC and L. mexicana CPB2.8, but not against mammalian CATHs B and L. It showed excellent IC50 against L. major promastigotes and amastigotes in vitro ${ }^{[103]}$.

Compounds containing an azide moiety were investigated for their inhibitory potency against CPB2.8DCTE. They were also tested for cytotoxicity against murine macrophages in vitro, and mutagenicity towards prokaryotic and eukaryotic cells. An alkylphosphocholine derivative (No. 4) exhibited the most potency against Leishmania promastigote and amastigotes, compared to pentamidine and amphotericin B, with lower toxicity as well as mutagenicity ${ }^{[104]}$. Recently, a new selective aziridinebased inhibitor was designed and it showed a timedependent inhibition of CPB2.8 $\triangle$ CTE. Docking studies confirmed the strong ionic interaction with the active site $^{[105]}$.

Moreover. nine benzophenones were evaluated for their potential inhibitory activity against $L$. amazonensis CPB2.8 and CPB3 as well as cruzain (CRZ), the major T. cruzi CP. Only one derivative (1c) exhibited selective activity towards the investigated CPs. When compared to amphotericin B, significant in vitro killing of intracellular amastigotes was observed $^{[106]}$. Utilizing enzymatic screening, thiophenes showed a moderate to excellent inhibitory activity by binding to CPB2.8 $\triangle$ CTE active site. The most promising compounds were selected for further evaluation regarding in vitro assays, docking studies as well as cytotoxicity and mutagenicity. Almost all investigated compounds, except one, acted as irreversible covalent inhibitors. Only compound $2 \mathrm{~b}$ showed a reversible covalent mechanism and was identified as a novel drug against leishmaniasis ${ }^{[107]}$. Similarly, searching in library database for compounds possessing a benzimidazole or an indole ring as scaffold, twelve compounds were synthesized for further evaluation. Four of them (9a-d) showed selective inhibitory activity against rLmCPB2.8 $\triangle$ CTE, without targeting mammalian CATHs. However, no clear correlation was observed between inhibitory activities against $r L m C P B 2.8 \Delta C T E$ and those against intracellular amastigotes. Although the most active compound (9d) proved to be more cytotoxic, it was the least permeating blood brain barrier, i.e. no neurotoxicity, when compared with 9a-c. It was 
concluded that 9d might be a new lead CPI for further drug design for treatment of leishmaniasis ${ }^{[108]}$.

As homology modeling of the mature L. mexicana CPB2.8 showed significant difference from bovine CATH B, the possibility of its evaluation as a good drug target was raised. A high throughput screening (HTS) for inhibitory compounds against rLmCPB2.8DCTE and bovine CATH B was conducted. Docking experiments with structural activity relation (SAR) analysis revealed that compounds containing triazine nitriles, semicarbazones and thiocarbazones suited better as peptidomimetic inhibitors of CPB2.8 $\triangle$ CTE rather than bovine CATH $\mathrm{B}^{[109]}$. Using a computer-aided approach, followed by homology modeling and docking studies, synthesized chalcone and chalcone-like compounds were evaluated for their inhibitory potency against Leishmania CPB. The promising compounds were selected for further in vitro evaluation as antileishmanial drugs as well as their cytotoxicity towards Vero cells. Only two compounds exhibited antileishmanial efficacy comparable to amphotericin B, with low cytotoxicity ${ }^{[110]}$.

\section{Cystatins (CYSs)}

British investigators observed that Leishmania promastigotes null mutants in the gene encoding chagasin were similar to WT parasites. Host-parasite interaction via modulating host CPs activity was suggested as a main role for Leishmania chagasin ${ }^{[111]}$. As previously described for chagasin structure, the investigators claimed that it was the only endogenous CPI with a cadherin-like immunoglobulin domain to be discovered in a non-metazoan. They also demonstrated the essential role played by the mobile loop in hostparasite interaction ${ }^{[112]}$. To evaluate the influence of chagasin in modulation of host immune response, its potentiality as novel drug target and/or vaccine candidate was studied. Ability of experimentally infected mice to control challenge infection with WT parasites was observed when vaccinated with chagasin over-expressing clone ${ }^{[113]}$. However, recombinant chagasin of $L$. mexicana did not inhibit midgut proteolytic enzymes extracted from Lutzomyia longipalpis, i.e., had no role in protection of Leishmania parasites in the vector ${ }^{[114]}$.

\section{Trypanosoma spp.}

\section{American trypanosomiasis}

Cysteine proteinases (CPs) of T. cruzi

Cruzipain (CRZ)

Historical background: Thirty years ago, cruzipain (CRZ), was known as a glycoprotein antigen (GP57/51). Its catalytic domain possessed $\mathrm{N}$-terminus homologous to $\mathrm{CP}$ sequence. It degraded proteins at a wide $\mathrm{pH}$ range and elicited $\mathrm{T}$ cell immune response ${ }^{[115]}$. Interestingly, CRZ displayed dual CATHs L and B specificity ${ }^{[116]}$. Several genes encoding CRZ (up to 130) were reported giving rise to CRZ isoforms with varying degrees of similarity ${ }^{[117,118]}$. Its crystal structure consists of a single polypeptide chain represented by two domains; $\alpha$-helical L domain and antiparallel $\beta$-sheet R domain ${ }^{[119]}$. It was highly accumulated and active in reservosomes, large round lysosome-like organelles located at the posterior end of T. cruzi epimastigotes ${ }^{[120]}$. Expression of CRZ was analyzed among three virulent $T$. cruzi isolates and their attenuated counterparts. Several bands of lower density in all attenuated strains were observed. Analysis of more isolates was recommended to investigate if attenuation was associated with change in CRZ sequence ${ }^{[121]}$.

Immunolocalization: It was reported that $T$. cruzi epimastigotes use two endocytic vesicles; cytostome/ cytopharynx complex and the flagellar pocket membrane, to ingest extracellular macromolecules to be stored in reservosomes ${ }^{[122]}$. Using a monoclonal antibody (mAb) against recombinant CRZ localized a $50 \mathrm{kDa}$ protein in reservosomes ${ }^{[123]}$. Later, endocytosis was visualized in intracellular amastigotes, and the digested extracellular macromolecules were stored in CRZ-positive lysosome-related structures (LRSs). The investigators suggested that LRSs were functionally related to reservosomes in epimastigotes ${ }^{[124]}$.

Genetic diversity: Expression levels and genetic diversity of CRZ isoforms varied among T. cruzi isolates as well as among T. cruzi-like species. This variation correlated with the observed levels of cellular invasion, differentiation, virulence and pathogenicity in the isolated strains. Eighty sequences of genes encoding CRZ from $25 T$. cruzi isolates and ten sequences of homologous CRZ encoding genes from $T$. cruzi-like species were comparatively analyzed. It was concluded that CRZ was a diagnostic and biogenetic marker beside its potentiality as drug target or vaccine candidate ${ }^{[125]}$.

Survival and virulence: The capability of host cells invasion by cultured trypomastigotes proved to be mediated by CRZ. Its expression activated host kininase II to degrade kinin. This was associated with overexpression of bradykinin B2 receptor. Inhibition of bradykinin degradation by kininase II potentiated host invasion. Accordingly, CRZ was suggested as a virulence factor ${ }^{[126]}$. Later, Scharfstein ${ }^{[127]}$ reviewed CRZ interactions with host CPs and endogenous CPI (chagasin). He claimed that CRZ interacted with both extravascular infection sites to produce Chagas' disease dynamics yielding inflammatory reactions associated with host immune response ${ }^{[127]}$.

Fibronectin was reported to be involved in microbe's adherence to host cells, serving as a barrier to prevent parasite invasion and migration. In an in vitro study, it was observed that when exogenous fibronectin exceeds CRZ concentration, a reduction occurs in metacyclic invasion into host cells. It was concluded that CRZ proteolytic activity played an essential role in fibronectin degradation, facilitating entry of the metacyclic forms, i.e. host cell invasion ${ }^{[128]}$. 
In addition, CRZ activated host TGF- $\beta$ signaling pathway that facilitates host cells invasion by T. cruzi. Addition of CATH inhibitor or chagasin inhibited and prevented TGF- $\beta$ activation, respectively. Also, T. cruzi invasion and intracellular growth were inhibited on addition of CATH CPI or anti-TGF- $\beta$ antibodies to Vero cell cultures. Therefore, CRZ was suggested as drug target in treatment of Chagas' disease ${ }^{[129]}$.

For the sake of parasites survival in Chagas' disease, two studies conducted in Argentine showed that CRZ devoid of enzymatic activity prevented apoptosis of cardiomyocytes. Two signaling pathways induced in vitro by CRZ were identified ${ }^{[130,131]}$. Another Argentinian study postulated that IL-6 mediates cell survival and host innate immune response through activation of transcription factor STAT3 via the glycoprotein gp130. The investigators observed that CRZ devoid of its enzymatic activity trigged toll-like receptor 2 (TLR2) to produce IL-6 that prevented apoptosis of cardiomyocyte in vitro. They also observed that cultured cardiomyocytes treated with active CRZ did not save them from apoptosis in spite of high IL-6 levels. This was attributed to CRZ proteolytic activity to inhibit STAT3 phosphorylation and to cleave recombinant gp130 in vitro. Accordingly, the investigators hypothesized that CRZ modified its strategy to confer cardiomyocytes protection induced by IL- 6 as antiapoptotic factor. Utilizing CRZ specific inhibitors was suggested to improve host immune activation with its cardio-protective effects ${ }^{[132]}$. Later, long term culture passages in cell lines of a single T. cruzi clone generated two different clones, one high and one low virulent strain. The investigators observed that the low virulent strain was three to five-fold less infective to mouse cardiomyocytes than the other. They also observed high CRZ expression from the highly virulent strain; hence it was concluded that CRZ contributed in T. cruzi growth, survival and virulence ${ }^{[133]}$.

Not only limited to vertebrate host, CRZ was also required for survival of $T$. cruzi in its vector. Adherence of T. cruzi epimastigotes to Rhodnius prolixus posterior midgut cells both ex vivo and in vivo was linked to CRZ. The investigators observed significant increased surface CRZ expression from epimastigotes isolated after passage in $R$. prolixus. Treatment with CYSs, E-64, chagasin and anti-CRZ antibodies significantly decreased parasites adhesion. The investigators concluded that CRZ was essential for successful colonization of $R$. prolixus by T. cruzi ${ }^{[134]}$.

Elicitation of host immune response: CRZ expression was responsible for induction of strong humoral and cellular immune response. Host antibodies were bound with cardiac myocin; i.e. autoimmune response, resulting in cardiological manifestations associated with Chagas' disease ${ }^{[135]}$. Host response immunomodulation was also reported because CRZ expression obliged infected macrophages to lose their pathway for production of pro-inflammatory cytokines. It was shown that CRZ up-regulated Th2 immune response by increased production of IL-10 and TGF- $\beta$, and down-regulated NO production. Macrophage trigging by CRZ expression, also known as alternative macrophage pathway; was suggested for the favor of parasite survival ${ }^{[136]}$. The role of CRZ in host immunoevasion was elucidated when the investigators evaluated macrophage response pathway in early infection with CRZ-deficient parasites in comparison to WT. In CRZ-deficient parasites, a rapid activation of host macrophage pathway was observed with increased levels of P65, a component of nuclear factor kappalight-chain-enhancer of activated B cells (NF- $\kappa B)$. It is worth mentioning that NF- $\mathrm{B}$ family members regulate innate and adaptive immune responses. In less than one hour, there was inability of intracellular growth and failure to survive inside infected macrophages. The investigators concluded that CRZ degraded NF- $\mathrm{\kappa B}$ P65 via its proteolytic activity to facilitate T. cruzi survival and replication ${ }^{[137]}$.

As it was previously reported that CRZ domain possessed unusual sulfate groups in its $\mathrm{N}$ terminus extension, BALB/c mice were immunized with purified CRZ and with its extension before and after desulfation treatment. Results revealed that sulfate groups were essential for IgG $2 b$ production and generation of memory T-cell responses. Ultrastructural alterations in heart tissue confirmed the essential role played by the sulfate groups ${ }^{[138]}$. Another team of scientists from Argentina and Germany investigated the role of sulfate groups in host immune response. Ability of glycopeptides containing sulfated groups to immunomodulate host immune response was observed for the sake of parasitemia and T. cruzi virulence $^{[139]}$. On the other hand, host innate immune response is mediated by production of reactive oxygen species (ROS) via phagocytes. It was demonstrated that CRZ induced ROS production in splenocytes from nonimmune and immune mice as well as in macrophage cell lines. It was also observed that CRZ increased production of IL- 6 and IL-1 $\beta^{[140]}$.

Egress: Role of CRZ in host-cell membrane permeability during egress cascade was described only in an American study. The investigators showed that chronically $T$. cruzi-infected mice produced antibodies that were bound with the surface of infected cells reducing parasite egress ${ }^{[141]}$.

\section{Applications \\ Biogenetic marker: Apolipoprotein A-I (Apo A-I) was previously identified as a potential diagnostic marker for Chagas' disease. Canadian investigators utilized Western blot to demonstrate Apo A-I susceptibility to CRZ proteolytic activity. The investigators concluded that CRZ contributed in production of Apo A-I truncation in the biomarker set ${ }^{[142]}$. On the other hand, dendrogram analyses based on presence/absence}


of CRZ and other proteases bands showed 50-60\% similarity between the assigned assemblages of $T$. cruzi (TCI and TCII) field isolates. It was demonstrated that protease expression profile of TCII isolates, in general, presented higher heterogeneity compared to TCI. However, CRZ expression did not show heterogeneous profile in TCII isolates ${ }^{[143]}$. Similar results were obtained when the same group of researchers investigated CRZ heterogeneity in 16 T. cruzi field isolates (eight of each assemblage). Stronger CRZ fluorescence labeling was observed more in TCI than in TCII isolates. Significant increased metacyclogenesis levels in vitro were also observed in TCI isolates ${ }^{[144]}$.

Utilizing anti-CRZ antibodies to identify CRZ profile in four T. cruzi sylvatic Z3 isolates showed an additional protein band with MW $80 \mathrm{kDa}$ only in one strain (SMM10). All strains showed a $40 \mathrm{kDa}$ protein band resembling that of CRZ activity ${ }^{[145]}$. Later, another study revealed molecular markers in sequencing genes encoding CRZ in related T. cruzi and T. cruzi-like species. Overall, the investigators identified valuable diagnostic markers for phylogenetic analyses of trypanosomes ${ }^{[125]}$.

Vaccine candidate: Recombinant CRZ with toll like receptor (TLR2/6), as an adjuvant, produced strong systemic and mucosal antibody responses. Significant cell-mediated immunity, associated with reduction of parasite burden and tissue damage was observed in immunized mice ${ }^{[146]}$. In CRZ immunization, increased survival rate of $B$ cells with increased IL-4 production in BALB/C (susceptible to cardiac autoimmunity) compared to C57BL/6 mice (resistant), was observed. The investigators concluded that CRZ immunization contributed in increasing host autoimmunity ${ }^{[147]}$. The role of attenuated Salmonella enterica, as a delivery system, carrying plasmid encoding CRZ was investigated. Naked CRZ-DNA or Salmonella CRZ DNA vaccine co-administered with a plasmid encoding granulocyte-macrophage colony-stimulating factor (GM-CSF), as an adjuvant were used. Individual vaccine showed significant protective and sustained Th1 response during acute infections, while combined vaccines prevented tissue damage during chronic infections. The investigators concluded that vaccine immunotherapy alone or in combination with other drugs represented a promising alternative regimen of treatment of Chagas' disease ${ }^{[148]}$.

\section{Calpains (CALPs)}

Employing whole-genome analysis, a total of 24 CALP-like proteins were characterized in T. cruzi ${ }^{[6]}$. Expression of the gene encoding TcCALP was identified during metacyclogenesis. Also, expression of CALPs and CALP-related proteins was associated with nutritional or environmental stress conditions. The investigators observed that TcCALP was 2.5 times more abundant in vector epimastigotes under nutritional stress than in epimastigotes growing in culture medium ${ }^{[149]}$. A calpain inhibitor was utilized to identify CALP-like CPs in T. cruzi epimastigotes. Significant in vitro growth rate reduction was observed after $48 \mathrm{~h}$. In addition, the investigators observed that TcCALP expression was reduced if epimastigotes were kept in axenic cultures for a long period ${ }^{[150]}$. Moreover, utilizing proteomic analysis of $T$. cruzi isolates with selected in vivo and in vitro resistance to benznidazole showed over expression of some proteins in resistant isolates, CALPs were among them. The investigators attributed this over expression to adaptation of the parasite to the unfavorable drug stress conditions ${ }^{[151]}$. Two other studies showed that CALP inhibitor inhibited the growth of $T$. cruzi clinically relevant forms ${ }^{[152]}$, and significantly reduced epimastigotes adherence to the insect luminal midgut ${ }^{[153]}$.

\section{Metacaspases (MCAs)}

Genomic analysis of T. cruzi revealed two genes encoding MCA3 and MCA5. While gene encoding MCA3 was composed of 16 copies per haploid genome, arrayed in two tandems, MCA5 was a single copy gene $^{[154]}$. Expression of TcMCA3 was observed in all developmental stages, whereas that of TcMCA5 was limited to epimastigotes ${ }^{[155]}$. Two studies concluded that characterization of both MCAs might lead to discovery of potential novel drugs ${ }^{[156,157]}$. In addition, TcMCA3 regulation was dependent on its interaction with host procaspase-activating compound 1 (PAC-1), a procaspase 3 activator, that reduced mammalian cells viability ${ }^{[157]}$.

Less studied CPs: A new CP, named TcCPmet, was identified when expressed during T. cruzi metacyclogenesis. The investigators observed its inhibition by a broad spectrum CPI (E-64). It had a different elution pattern than that of CRZ, and was not recognized by anti-CRZ serum. It was able to hydrolyze peptides as CRZ, but at alkaline $\mathrm{pH}^{[158]}$. However, it was reported later that active proteases at acid $\mathrm{pH}$ are CPs, while those active at alkaline $\mathrm{pH}$ are metalloproteases ${ }^{[143]}$. For ATGs, a study demonstrated Atg4 and Atg8 over expression during differentiation of the developmental stages ${ }^{[159]}$.

\section{Cysteine protease inhibitors (CPIs)}

All the investigated proteinase inhibitors (AMK, two DMK derivatives) demonstrated significant potentiality as anti-chagasic drugs. The first was the most efficient CRZ inhibitor, while DMKs showed no potency against epimastigotes $^{[160]}$. The potential use of NO donors (NOR-3, SIN-1, SNAP, and SNP) was investigated in treatment of Chagas' disease and falciparum malaria. It was shown that NO donors inhibited CPs action via their cysteine catalytic residue ${ }^{[161]}$.

As previously reviewed ${ }^{[162]}$, peptide inhibitors gave in vivo unsatisfactory results due to their poor pharmacological profiles and their susceptibility to degradation by host CPs. Therefore, it was recommended to conduct structure-based screening 
studies to identify new non-peptide and peptidomimetic inhibitors competent with CRZ crystal structure. Several studies utilized compounds containing nitrile group to be investigated as peptide CRZ inhibitors. Mexican investigators discussed structural features to improve the biological activity of nitrile group as potent peptide CRZ inhibitor ${ }^{[163]}$. Odanacatib (MK-0822), a drug containing nitrile group, was established as a potent reversible inhibitor for human CATH K. Sequence similarity between CRZ and CATH K encouraged Canadian investigators to evaluate odanacatib as CRZ inhibitor. They found that MK-0822 exhibited selective inhibitory potency against CRZ compared to human CATHs. Further optimization of odanacatib analogs enabled the investigators to identify two CPIs (Cz007 and Cz008) that showed both in vitro and in vivo efficacy in treatment of Chagas' disease. Besides, it was orally bioavailable, well tolerated, and with low cytotoxicity. Compound $\mathrm{Cz} 007$ in a daily dose of $3 \mathrm{mg} / \mathrm{kg}$ gave a $90 \%$ cure rate with $100 \%$ survival rate ${ }^{[164]}$. Followed by SAR studies, dipeptidyl nitrile scaffold were synthesized and investigated as potent CRZ inhibitors. For the SAR studies, the investigators assigned three, eleven and twelve substitutions at the P1, P2 and P3 positions of a dipeptidyl nitrile scaffold, respectively. The 23 lead inhibitors exhibited in vitro trypanocidal activity, however compound 12 was the most potent. Although no clear relationship was observed between CRZ inhibitory potency and trypanocidal activity, they claimed that such approach represented a valuable guide for identification of novel CRZ inhibitors for Chagas' disease treatment ${ }^{[165]}$.

Non-peptide CRZ inhibitors were investigated, the most common were semicarbazone derivatives. One of thiosemicarbazone derivatives combined with the aromatic protein of isatin scaffold was reported as potent $\mathrm{CRZ}$ inhibitor ${ }^{[166]}$. Novel series of semicarbazone and aldehyde-based non-peptide CRZ inhibitors were designed and synthesized in two American studies. The investigators demonstrated and validated utilizing SARs studies for lead compound optimization $^{[167,168]}$. Similar results were obtained when Brazilian scientists investigated a series of thiosemicarbazone and semicarbazone derivatives as CRZ inhibitors ${ }^{[169]}$. Later, three other studies were conducted in Brazil for semicarbazone derivatives. The first study synthesized novel derivatives that proved to inhibit $T$. cruzi growth through an apoptotic pathway, not as CRZ inhibitor ${ }^{[170]}$. To optimize the activity of a thiosemicarbazone derivative, a 1,3-thiazole core was used in the second study, leading to identification of a potent CRZ inhibitor. Utilizing electron microscopy, compound (1c) showed irreversible and specific morphological alterations ${ }^{[171]}$. Series of semicarbazone, thiosemicarbazone, and aminoguanidine derivatives were synthesized and investigated as CRZ inhibitors. All derivatives demonstrated CRZ inhibition in a range of $70-75 \%$ with IC50 values against epimastigotes ranging from 20-140 $\mu \mathrm{M}$. Utilizing docking studies, the investigators concluded that these derivatives were CRZ inhibitors attacking its cysteine residue, and they recommended further studies to validate optimization of such compounds ${ }^{[172]}$.

Vinyl sulfones also gained much attention as peptidomimetic CRZ inhibitors. Twenty years ago, K777 was utilized in treatment of Chagas' diseases, and it proved to clear parasitemia in chronically infected mice after 3 weeks of administration ${ }^{[173]}$. The same group of investigators evaluated the potentiality of T. cruzi to resist K777 administration for long time. They generated K777-resistant epimastigotes in vitro and found that resistance to 20 -fold of its lethal concentration occurred after a year of gradual drug increase. Negligible CRZ expression was observed in resistant epimastigote extracts compared to the original control, and its activity was restored following drug withdrawal ${ }^{[174]}$. Later, the same inhibitor was used in T. cruzi-infected dogs and it prevented cardiomyopathy after a week of treatment ${ }^{[175]}$.

In their review aiming to discover new drug targets for treatment of Chagas' diseases, American scientists assigned two approaches. One of them had led to the discovery of K777 as a clinical drug candidate. They claimed that further improvement of K777 required searching for new scaffolds using molecular docking studies in screening ZINC database; the public library of commercially available compounds prepared especially for virtual screening ${ }^{[176]}$. Recently, all reports that utilized SAR studies after virtual or HTS were also reviewed. The reviewers concluded that non-peptide inhibitor; vinyl sulfone WRR-669 showed both in vitro and in vivo efficacy against Chagas' disease ${ }^{[177]}$.

A new strategy was proposed to design CRZ nonpeptide inhibitor. Utilizing substrate activity screening (SAS), a new class of non-peptide triazole-based ketone inhibitors targeting CRZ was identified. High selective potency towards CRZ was improved on addition of a binding interaction in CRZ S3 pocket, i.e. incorporated with $\beta$-chloro vinyl sulfone pharmacophore. The new inhibitor showed complete eradication of T. cruzi from mammalian cell cultures ${ }^{[178]}$. Two years later, the same group of investigators utilizing CRZ high-resolution crystal structure confirmed its inhibition by this class of new inhibitors. Two intraperitoneal injections of a $20 \mathrm{mg} / \mathrm{kg}$ daily dose for 27 days revealed promising results in experimentally infected mice ${ }^{[179]}$.

Quinoxaline-N-acylhydrazone derivatives showed inhibitory potency against T. cruzi epimastigotes in vitro ${ }^{[180]}$. In a project to discover non-peptide CRZ inhibitors, the investigators utilized a combination of HTS, docking and co-crystallization studies to identify ML217. It exhibited in vitro trypanocidal activity with minimal cytotoxicity effects and in vivo efficacy in $T$. cruzi-infected mice ${ }^{[181]}$. Compounds WRR-483 and WRR-669 which are synthesized oxyguanidine analogs, 
exhibited satisfactory results. The SARstudies confirmed the non-covalent binding of WRR-669 in CRZ crystal structure $^{[182]}$. Computer-guided approach succeeded to identify clofazimine and benidipine with trypanocidal effects through their CRZ inhibitory potency. Results revealed that combined treatment reduced parasite burden in the cardiac muscle of chronically infected mice through a synergism mechanism ${ }^{[183]}$. Oxadiazoles were also suggested as potential scaffolds to be utilized in developing novel non-peptide CRZ inhibitors ${ }^{[184]}$.

Recently, a gene mutation in a non-active site of one of the genes encoding CRZ was observed. The investigators suggested that this discovery may open a new field of alternative inhibitor design ${ }^{[185]}$. Aiming to discover new scaffolds as CRZ inhibitors, Korean investigators utilized pharmacophore virtual screening, followed by molecular docking and molecular dynamics simulations. This was followed by SAR studies that specifically demonstrate CPI interactions with the catalytic residues to be locked at the $\mathrm{S} 1, \mathrm{~S} 2$ and $\mathrm{S} 3$ subsites of CRZ. Utilizing this strategy, the investigators demonstrated that the two compounds selected as potential drugs for treatment of Chagas' disease were locked in CRZ active sites. Furthermore, both compounds recorded higher molecular dock scores and lower binding energies ${ }^{[186]}$.

\section{Cystatins (CYSs)}

Chagasin of $T$. cruzi was first isolated, immunolocalized and biochemically characterized by Monteiro et al., ${ }^{[13]}$. Immunoblotting revealed that its expression was developmentally regulated and inversely correlated with CRZ expression. It was immunolocalized on the amastigote' surface and trypomastigotes flagellar pocket ${ }^{[13]}$. Variable expression levels were observed among six $T$. cruzi strains, with lower levels in avirulent isolates (i.e. poorly infective). The investigators concluded that chagasin indirectly modulated CRZ proteolytic functions, and played an essential role in epimastigote susceptibility to synthetic CPIs and their differentiation to metacyclic trypanosomes as well as T. cruzi virulence ${ }^{[187]}$. Interestingly, the non-infectivity of winged bugs by $T$. cruzi was attributed to CRZ modulation by tigutcystatin. The latter is the expressed CYS from the anterior midgut of Triatoma infestans ${ }^{[188]}$.

\section{African trypanosomiasis Cysteine proteinases (CPs) of T. brucei Cathepsins (CATHs)}

In 1992, Kenyan investigators purified a CATH-Llike CP from bloodstream and metacyclic forms of $T$. congolense, and the term of trypanopain-Tc was raised. The enzyme showed proteolytic activity towards fibrinogen, serum albumin and trypanosome variantsurface glycoprotein (VSG) ${ }^{[189]}$. At the beginning of $20^{\text {th }}$ century, the term rhodesain was introduced when American investigators purified it from $T$. $b$. rhodesiense. It was immunolocalized in the lysosome in all life cycle stages. However, its expression was five times greater in short stumpy trypanosomes ${ }^{[190]}$. Two CATHs (B and L) were reported in T. $b$. brucei and T. congolense, and their corresponding CATHL was termed brucipain ${ }^{[191]}$ and congopain ${ }^{[192]}$, respectively.

Utilizing gene knockout for both genes encoding CATHs showed that CATHB, not rhodesain played an essential role for T. brucei survival in vitro ${ }^{[193]}$. In spite of that, rhodesain (CATHL), rather than CATHB, was suggested as an appropriate drug target. Nonspecific CATH inhibitors killed cultured parasites with $>99 \%$ inhibition of both CATHs, while specific CATHB inhibitors did not affect parasite survival. In contrast, specific CATHL inhibitors killed parasites with $>99 \%$ inhibition of CATHL, but only $70 \%$ CATHB inhibition ${ }^{[194]}$. Other functions were reported; expression of CATHB mediated degradation of host transferrin in the endosomal/lysosomal compartment ${ }^{[193,195]}$; while expression of CATHL of T. b. gambiense and T. b. brucei protected parasites in vitro against lysis ${ }^{[196-197]}$.

It is known that BBB is composed of brain microvascular endothelial cells (BMECs) especially designed to keep pathogens out. In their in vitro studies, the investigators observed that human-infective bloodstream forms of T. $b$. gambiense crossed BBB more efficiently than those derived from $T . b$. bruceiinfected animals. Enhancement of cross barrier by $T$. $b$. brucei was observed if incubated with brucipainrich supernatants expressed from $T$. $b$. gambiense. Accordingly, the investigators attributed BBB crossing in T. b. gambiense to the capability of brucipain to generate $\mathrm{Ca}^{2+}$ activation signals in human brain microvascular endothelial cells. This is required for dynamics modulation and integrity of the endothelial cell monolayers leading to trans-endothelial migration through human $\mathrm{BBB}^{[198]}$.

\section{Applications of CATHs in diagnosis and genotyping}

During the period 2009-2014, several publications from Brazil reported utilizing CARHs for diagnosis and genotyping. A specific sequence in the gene encoding rangelipain, a CATH L-like CP from $T$. rangeli, showed homologous sequence in 17 isolates from humans and wild mammals. Rangelipain was validated as an excellent diagnostic marker for diagnosis and genotyping of $T$. rangeli by $\mathrm{PCR}^{[199]}$. Characterized sequences from genes encoding CATH L-like CPs from T. vivax isolated from African and South American cattle were investigated as biogenetic markers. Phylogenetic studies revealed two genotypes; cattle isolates from West Africa and South America belonged to T. vivax genotype, whereas cattle isolates from East Africa showed divergent sequences and belonged to T. vivaxlike genotype ${ }^{[200]}$. Analysis of 78CATHL catalytic domain sequences from $22 T$. theileri isolated from cattle, water buffalo and deer identified six genotypes utilizing PCR. The investigators validated these sequences for population genotyping and evolutionary studies ${ }^{[201]}$. 
The same group of investigators concluded usefulness of the CATHL catalytic domain sequences to identify two genotypes of $T$. theileri in cattle ${ }^{[202]}$. Similarly, $T$. congolense is a complex of three subgroups (Savannah, Forest and Kilifi) differing in virulence, pathogenicity, drug resistance, vectors, as well as geographical distribution. The same group of investigators compared sequences of genes encoding congopain from Savannah genome database and those of the three T. congolense subgroups. The obtained diverging results encouraged the investigators to develop PCR assay targeting congopain sequences to diagnose and differentiate between the three subgroups ${ }^{[203]}$.

\section{Calpains (CALPs)}

Several genes encoding CALPs were identified in T. brucei. El-Sayed et al. ${ }^{[204]}$, in their bioinformatics analysis, pointed to the presence of a family of at least nine proteins (TbCALP1.1-9) with some degree of similarity to CALP proteolytic domain, but devoid of calcium-binding domains. Employing wholegenome analysis, a total of 18 CALP-like proteins were characterized in T. brucei and the investigators suggested their involvement in diverse cellular functions ${ }^{[6]}$.

An ortholog TbCALP4.1, also termed CALP5.5, was characterized as a cytoskeleton-associated protein exclusively detected in epimastigotes. The British investigators suggested that CALP5.5 was essential for cell morphogenesis ${ }^{[205]}$. Another British study reported stage-specific expression of CALP5.5 essential for $T$. brucei procyclic morphogenesis inside tsetse mid-gut ${ }^{[206]}$. A comprehensive analysis of the expression and transcription patterns of CALPrelated proteins in T. brucei was conducted. It was found that a small kinetoplastid CALP-related protein (SKCRP5.1) and CALPs 8.1 and 5.5 were differentially expressed in trypomastigotes, while transcripts of SKCRP1.6, SKCRP7.2 and CALPs 4.1 and 5.5 were in epimastigotes $^{[207]}$. Later, SKCRPs 7.1 and 7.2 were identified in $T$. brucei under persistent endoplasmic reticulum stress. The investigators concluded the essential role played by SKCRPs to induce PCD in under-stressed parasites ${ }^{[208]}$.

\section{Metacaspases (MCAs)}

Five genes encoding MCAs were identified in $T$. brucei, of which only MCAs 2 and 3 were expressed in the bloodstream forms, while MCA5 was expressed in the procyclic forms. It was found that only MCA5 possessed an additional C-terminal extension. Whereas MCAs 2, 3 and 5 possessed cysteine and histidine residues required for CP proteolytic activity, MCA1 and MCA4 lack both residues, and have a serine substitution instead of cysteine. Therefore, they lack usual cysteine catalytic activity ${ }^{[209]}$. On deletion of genes encoding MCA2 or MCA3 with MCA5 $(\Delta$ mca $2 / 3 \Delta$ mca5), the investigators observed successful growth of mutant parasites in vitro and in vivo. It was attributed to compensative overlap function of MCAs 2 and 3 . There was no change in the susceptibility of $T$. brucei to stress, similar to WT. On simultaneous deletion of all genes, immediate growth arrest was observed. The investigators recommended further studies to elucidate roles of MCAs in PCD machinery pathway in $T$. bruce $^{[210]}$. In a British study, recombinant T. brucei MCA 2 (TbMCA2) showed calcium-dependent proteolytic activity. It was claimed that TbMCA2 activity was different from that of caspases suggesting its different physiological roles in T. brucei ${ }^{[211]}$.

During the period, 2012-2017, a team of scientists from Brazil and UK published three reports. The crystal structure of TbMCA2 was determined and revealed procession of an unusual $\mathrm{N}$ terminus that regulated substrate access to the active site. In the presence of its specific substrate, TbMCA2 was activated by calcium. Utilizing phylogenetic analysis, the investigators suggested that caspases and TbMCAs evolved from a common ancestor, but independently showed distinct activation mechanisms to regulate PCD pathways. Accordingly, the investigators recommended future studies to design MCA specific inhibitors for development of novel anti-protozoal drugs ${ }^{[212]}$. In the second report which utilized TbMCA2 crystal structure, four observations were demonstrated; 1) strict preference for charged basic amino acid, e.g. arginine or lysine at the $\mathrm{P} 1$ position; 2) non-basic residues at P1 were competitive TbMCA2 inhibitors; 3) negative charged residues, e.g. asparagine and glutathione at P2 and $\mathrm{P} 3$ positions were resistant to TbMCA2 hydrolysis, and 4) two $\mathrm{Ca}^{2+}$-binding sites with reversible structural modification were close to the S2 binding pocket upon $\mathrm{Ca}^{2+}$ activation. Interestingly, one $\mathrm{Ca}^{2+}$-binding site was localized on the surface of asparagine residue (Asp ${ }^{173}$, $\mathrm{Asp}^{189}$, $\mathrm{Asp}^{190}$ and $\mathrm{Asp}^{220}$ ), a location distinct from both the catalytic active site and the $\mathrm{S} 2$ binding pocket ${ }^{[10]}$. The third article reported that TbMCA2 was active without processing, and cleavages at lysine ${ }^{55}$ and lysine $e^{268}$ increased its activity on synthetic substrates ${ }^{[213]}$. Recently, South African investigators biochemically characterized T. congolense MCA5 aiming to develop novel drugs for treatment of livestock trypanosomiasis. Similar results were obtained for substrate preference and $\mathrm{Ca}^{+2}$-binding prior to activation, as previously reported for TbMCA2 $2^{[214]}$.

Based on the previous mention that T. brucei MCAs 1 and 4 had active site substitutions and lacked proteolytic activity, a study reported TbMCA4 as virulence factor. Parasites mutant in gene encoding TbMCA4 showed normal growth in vitro, but significant reduced virulence in vivo. It was demonstrated that MCA4 was expressed only in bloodstream forms due to its specific processing by MCA3, i.e. MCA4 requires MCA3 to be processed as proteolytic enzyme. It was concluded that TbMCA4 was a pseudo-peptidase, but it was linked as virulence factor due to its association with MCA3 in its proteolytic cascade. Future studies 
were recommended to investigate MCA4 role in natural chronic infections ${ }^{[215]}$.

\section{Cysteine proteinase inhibitors (CPIs)}

Several compounds were investigated as antitrypanosomal chemotherapeutic agents through their inhibitory effects on brucipain. These included nonpeptide ${ }^{[216-221]}$ and peptidomimetic ${ }^{[222-224]}$ inhibitors.

Non-peptide inhibitors: Quantitative HTS approach utilized to search for a CRZ inhibitor identified new compounds of triazine nitriles. Three studies were conducted in USA. In the first study, structural scaffold modifications that improved their in vitro potency against both CRZ and rhodesain were performed. The selected lead compounds that showed higher selectivity to CRZ and rhodesain than human CATHs, also showed significant inhibitory potency against $T$. brucei in vitro ${ }^{[216]}$. Oral administration of one of the lead compounds showed significant increase of survival rate and time in T. b. brucei-infected mice, but with a little effect on T. $b$. rhodesiense-infected mice. Moreover, it showed high potency to cross $\mathrm{BBB}^{[217]}$. Utilizing SAR analyses of the lead triazine nitriles, the investigators were able to identify the binding preferences of CRZ and rhodesain active site, individually; i.e. its S2 pocket. Imidazopyridine nitrile showed significant stability and selectivity toward the active site of both CPs. Moreover, it showed a fourfold lower cytotoxicity than the parent triazine nitrile ${ }^{[218]}$.

Dipeptide nitriles, a new class of potent non-peptide CPIs against papain-like proteases were investigated. The investigators synthesized compounds that showed inhibitory potency against recombinant CPs of T. brucei (rhodesain and CATHB) as well as CRZ. They succeeded to generate activity-based probes serving as tools for further development of synthesized azanitriles as potential anti-trypanosomal drugs ${ }^{[219]}$. Later, a series of dipeptide nitriles known to inhibit mammalian CATHs were investigated against rhodesain. Based on SAR analyses, the investigators observed that compound 35 possessed a leucine residue and a phenyl ring to fit into S2 and S3 pockets of rhodesain, respectively ${ }^{[20]}$. On the other hand, the inhibitory activity of niacin, one of nicotinamide derivatives, on T. brucei growth was investigated. Electron microscopy revealed severe defects in endocytic traffic with enlargement of the flagellar pocket, and lysosomal disruption ended with trypanosomes death. A direct inhibitory activity assay of recombinant $\mathrm{TbCATHB}$ confirmed its mechanism of action as CPI. Due to several reasons including being cheaply produced, oral administration, BBB crossing, and interference with trypanosomes iron metabolism, nicotinamide derivatives were suggested as a new class of anti-trypanosomal drugs ${ }^{[221]}$.

Peptidomimetic inhibitors: It was found that vinyl sulfones had a potentiality to serve as Michael acceptors for the nucleophilic active site cysteine. The investigators recommended further studies to synthesize second generation of vinyl sulfones ${ }^{[222]}$. Utilizing structure-guided approach, two new classes of synthesized vinyl sulfones were identified, and their IC50 against rhodesain, TbCATHB and CRZ were determined. Results revealed that analogs 7 and 8 targeted S2 and S3 of all investigated CATHs. When evaluated in vitro, they showed efficient potency against T. b. brucei, without significant cytotoxicity effects $^{[223]}$. The efficacy of K11777, combined with current drugs used for African trypanosomiasis, such as suramin, pentamidine, melarsoprol and eflornithine, on T. brucei bloodstream forms in vitro, was investigated. A synergistic effect was observed after treatment of K11777 with eflornithine, in contrast to antagonistic effects shown with the other drugs ${ }^{[224]}$.

\section{Cystatins (CYSs)}

To investigate the role played by T. brucei chagasin, a group of scientists from Brazil and UK generated chagasin-mutant bloodstream forms. Function regulation of $T$. brucei CPs was suggested through modulating surface coat exchange during differentiation, degrading IgG against VSGs, and immunomodulating host immune response, thus increasing its infectivity and virulence ${ }^{[225]}$.

\section{CONCLUDING REMARKS}

1. There are three CPs (CATHs, CALPs and MCAs) and only one endogenous CPI (chagasin) in pathogenic trypanosomatids: Leishmania spp., T. cruzi and T. brucei. All CATHs possess a long C-terminus extension (CTE), and they play crucial roles in parasite virulence, and elicit host immune response. With special emphasis on CRZ, all genes encoding CPs were investigated as drug targets, diagnostic and biogenetic markers, as well as vaccine candidates.

2. Genomic analysis identified several genes encoding CALPs with significant potentiality as drug targets. A total of 27, 24 and 18 CALP-like proteins were characterized in L. major, T. cruzi and T. brucei, respectively. According to their structure, small kinetoplastid CALP-related proteins (SKCRPs) possess an exclusive $\mathrm{N}$-terminus prodomain. It was reported that T. brucei possessed several SKCRPs, differentially expressed in all its developmental stages under persistent endoplasmic reticulum stress.

3. An important difference was reported for all trypanosomatids MCAs; they require calcium prior to activation. No evidence was shown to be involved in PCD, all studies concluded that their role in autophagy is essentially for proliferation and differentiation.

4. L. donovani and T. cruzi possess two MCAs. In T. cruzi, gene encoding MCA3 is composed of 16 copies, while a single copy encoding MCA5 was observed. Although five MCAs were identified in T. brucei, only MCAs 2, 3 and 5 possessed cysteine and histidine residues required for CP proteolytic 
activity. On the other hand, MCA1 and MCA4 lack both residues, with a serine substitution instead of cysteine, hence they lack usual cysteine catalytic activity.

5. Chagasin has unique immunoglobulin fold, acting as scaffold for three loops of highly conserved sequences. It has a specific mode of interaction with CPs that is different from other CYSs previously reported in parasites. Hence, it is placed by MEROPS website in a recent classification as clan IX, family I42. Host-parasite interaction via modulating host immune response and host CPs activity was suggested as a main role for chagasin.

6. Leishmania spp. include three CATHs: two L-like (CPA and $\mathrm{CPB}$ ) and one B-like (CPC). A single copy of each gene encoding CPA and CPC were identified, while that encoding CPB is a multi-copygene located in a single locus and arranged in a tandem repeat. It was reported that gene expression of copy $c p b 2$ was mainly in metacyclic forms, and those of last 16 copies (cpb3-cpb18) were in amastigotes. The copy $c p b 2.8$ without its CTE was suggested as an immunomodulator of Th1/Th2 immune response.

7. Because man is infected by several Leishmania spp., CATHs expression was attributed for variable clinical presentations in CL and VL, with specific emphasis on CATH B. The latter was also confirmed as virulence factor due to its essential roles in parasite growth, viability, autophagy, differentiation and host cell invasion.

8. Several genes encoding CRZ were reported giving rise to several isoforms with varying degrees of genetic diversity. It was immunolocalized in lysosomes of amastigotes and trypomastigotes and reservosomes of epimastigotes. Beside its role in T. cruzi survival, egress and virulence, its expression was responsible for induction of strong humoral and cellular immune responses resulting in cardiological manifestations associated with Chagas' disease. Its domain possesses unusual sulfate groups in its $\mathrm{N}$ terminus extension that proved to immunomodulate host immune response.

9. Brucipain, rhodesain and congopain are terms used for CATH L-like CPs of T. b. brucei, T. b. rhodesiense, and $T$. congolense, respectively. It was suggested that crossing of $T$. $b$. brucei to BBB was attributed to brucipain capability to generate $\mathrm{Ca}^{2+}$ activation signals in human brains, required for dynamics modulation and integrity of the endothelial cell monolayers. Also, congopain gained much attention due to its essential roles in cattle trypanosomiasis as it was widely investigated as vaccine candidate.

10. Several compounds, investigated as CPIs, proved high potency against Leishmania CATHs, CRZ and rhodesain or its analogs. However, vinyl sulfones, semicarbazone derivatives and triazole-based ketone inhibitors gained much attention. To design novel non-peptide CPIs, several studies documented utilizing a combination of virtual screening or HTS, docking studies and SAR analysis using target $\mathrm{CP}$ crystal structure.

Conflict of interest: There is no conflict of interest.

\section{REFERENCES}

1. Ferreira LG, Andricopulo AD. Targeting cysteine proteases in trypanosomatid disease drug discovery. Pharmacol Ther 2017; 180:49-61.

2. Rocha DA, Silva EB, Fortes IS, Lopes MS, Ferreira RS, Andrade SF. Synthesis and structure-activity relationship studies of cruzain and rhodesain inhibitors. Eur J Med Chem 2018; 157:1426-1459.

3. Siqueira-Neto JL, Debnath A, McCall LI, Bernatchez JA, Ndao M, Reed SL, et al. Cysteine proteases in protozoan parasites. PLoS Negl Trop Dis 2018; 12(8):e0006512.

4. Machado PA, Carneiro MPD, Sousa-Batista AJ, Lopes FJP, Lima APCA, Chaves SP, et al. Leishmanicidal therapy targeted to parasite proteases. Life Sci 2019; 219:163-181.

5. Goll DE, Thompson VF, Li H, Wei W, Cong J. The calpain system. Physiol Rev 2003; 83:801-831.

6. Ersfeld K, Barraclough H, Gull K. Evolutionary relationships and protein domain architecture in an expanded calpain superfamily in kinetoplastid parasites. J Mol Evol 2005; 61:742-757.

7. Branquinha MH, Marinho FA, Sangenito LS, Oliveira SSC, Gonçalves KC, Ennes-Vidal V, et al. Calpains: potential targets for alternative chemotherapeutic intervention against human pathogenic trypanosomatids. Curr Med Chem 2013; 20(25): 3174-3185.

8. Reggiori F, Klionsky DJ. Autophagosomes: biogenesis from scratch? Curr Opin Cell Biol 2005; 17:415-422.

9. González IJ. Metacaspases and their role in the life cycle of human protozoan parasites. Biomedica 2009; 29:485-493.

10. Machado MF, Marcondes MF, Juliano MA, McLuskey $\mathrm{K}$, Mottram JC, Moss CX, et al. Substrate specificity and the effect of calcium on Trypanosoma brucei metacaspase 2. FEBS J 2013; 280(11):2608-2621.

11. Menna-Barreto RFS. Cell death pathways in pathogenic trypanosomatids: lessons of (over) kill. Cell Death Dis 2019; 10(2): 93.

12. Grewal JS, McLuskey K, Das D, Myburgh E, Wilkes J, Brown E, et al. PNT1 is a C11 cysteine peptidase essential for replication of the trypanosome kinetoplast. J Biol Chem 2016; 291(18):9492-9500.

13. Monteiro AC, Abrahamson M, Lima AP, VannierSantos MA, Scharfstein J. Identification, characterization and localization of chagasin, a tight-binding cysteine protease inhibitor in Trypanosoma cruzi. J Cell Sci 2001; 114(21):39333942.

14. Sanderson SJ, Westrop GD, Scharfstein J, Mottram JC, Coombs GH. Functional conservation of a 
natural cysteine peptidase inhibitor in protozoan and bacterial pathogens. FEBS Lett 2003; 542(13):12-16.

15. Wang SX, Pandey KC, Scharfstein J, Whisstock J, Huang RK, Jacobelli J, et al. The structure of chagasin in complex with a cysteine protease clarifies the binding mode and evolution of an inhibitor family. Structure 2007; 15(5):535-543.

16. MEROPS. http://www.merops.sanger.ac.uk. Release 11.0, last update: 6 June, 2019.

17. Silva-Almeida $M$, Pereira BA, Ribeiro-Guimarães ML, Alves CR. Proteinases as virulence factors in Leishmania spp. infection in mammals. Parasit Vectors 2012; 5:160.

18. Silva-Almeida M, Souza-Silva F, Pereira BA, Ribeiro-Guimarães ML, Alves CR. Overview of the organization of protease genes in the genome of Leishmania spp. Parasit Vectors 2014; 7:387.

19. Olivier M, Gregory DJ, Forget G. Subversion mechanisms by which Leishmania parasites can escape the host immune response: a signaling point of view. Clin Microbiol Rev 2005; 18(2): 293305.

20. Souza AE, Waugh S, Coombs GH, Mottram JC. Characterization of a multi-copy gene for a major stage-specific cysteine proteinase of Leishmania mexicana. FEBS Lett 1992; 311(2):124-127.

21. Mottram JC, Robertson CD, Coombs GH, Barry JD. A developmentally regulated cysteine proteinase gene of Leishmania mexicana. Mol Microbiol. 1992; 6(14):1925-1932.

22. Brooks DR, Denise H, Westrop GD, Coombs GH, Mottram JC. The stage-regulated expression of Leishmania mexicana CPB cysteine proteases is mediated by an intercistronic sequence element. J Biol Chem 2001; 276(50):47061-47069.

23. Mundodi V, Somanna A, Farrell PJ, Gedamu L. Genomic organization and functional expression of differentially regulated cysteine protease genes of Leishmania donovani complex. Gene 2002; 282(12):257-265.

24. Mottram JC, Coombs GH, Alexander J. Cysteine peptidases as virulence factors of Leishmania. Curr Opin Microbiol 2004; 7: 375-381.

25. Hide M, Bras-Gonçalves R, Bañuls AL. Specific CPB copies within the Leishmania donovani complex: evolutionary interpretations and potential clinical implications in humans. Parasitology 2007; 134(3):379-389.

26. Turk V, Stoka V, Vasiljeva O, Renko M, Sun T, Turk B, et al. Cysteine cathepsins: from structure, function and regulation to new frontiers. Biochim Biophys Acta 2012; 1824(1):68-88.

27. Santos-de-Souza R, Souza-Silva F, de AlbuquerqueMelo BC, Ribeiro-Guimarães ML, de Castro Côrtes LM, Pereira BAS, et al. Insights into the tracking of the cysteine proteinase $\mathrm{B} \mathrm{COOH}$ terminus polypeptide of Leishmania (Leishmania) amazonensis by surface plasmon resonance. Parasitol Res 2019; 118(4):1249-1259.
28. Buxbaum LU, Denise H, Coombs GH, Alexander J, Mottram JC, Scott P. Cysteine protease B of Leishmania mexicana inhibits host Th1 responses and protective immunity. J Immunol 2003; 171(7):3711-3717.

29. Lasakosvitsch F, Gentil LG, dos Santos MRM, da Silveiri JF, Barbieri CL. Cloning and characterization of a cysteine proteinase gene expressed in amastigotes of Leishmania (L.) amazonensis. Int J Parasitol 2003; 33:445-454.

30. Mundodi V, Kucknoor AS, Gedamu L. Role of Leishmania (Leishmania) chagasi amastigote cysteine protease in intracellular parasite survival: studies by gene disruption and antisense mRNA inhibition. BMC Mol Biol 2005 3;6:3.

31. Ueda-Nakamura $\mathrm{T}$, Attias $\mathrm{M}$, de Souza $\mathrm{W}$. Comparative analysis of megasomes in members of the Leishmania mexicana complex. Res Microbiol 2007; 158(5):456-462.

32. Lanfranco MF, Loayza-Muro R, Clark D, Núñez $\mathrm{R}$, Zavaleta $\mathrm{AI}$, Jimenez $\mathrm{M}$, et al. Expression and substrate specificity of a recombinant cysteine proteinase B of Leishmania braziliensis. Mol Biochem Parasitol 2008; 161(2):91-100.

33. de Araújo Soares RM, dos Santos AL, Bonaldo MC, de Andrade AF, Alviano CS, Angluster J, et al. Leishmania (Leishmania) amazonensis: differential expression of proteinases and cellsurface polypeptides in avirulent and virulent promastigotes. Exp Parasitol 2003; 104(3-4):104112.

34. Gantt K, Schultz-Cherry S, Rodriguez N, Jeronimo $\mathrm{S}$, Nascimento E, Goldman T, et al. Activation of TGF-beta by Leishmania chagasi: importance for parasite survival in macrophages. J Immunol 2003; 170(5):2613-2620.

35. Mahmoudzadeh-Niknam $\mathrm{H}$, McKerrow JH. Leishmania tropica: cysteine proteases are essential for growth and pathogenicity. Exp Parasitol 2004; 106(3-4):158-163.

36. Alexander J, Coombs GH, Mottram JC. Leishmania mexicana cysteine proteinase-deficient mutants have attenuated virulence for mice and potentiate a Th1 response. J Immunol 1998; 161(12):67946801.

37. Frame MJ, Mottram JC, Coombs GH. Analysis of the roles of cysteine proteinases of Leishmania mexicana in the host-parasite interaction. Parasitology 2000; 121(4):367-377.

38. Denise H, McNeil K, Brooks DR, Alexander J, Coombs GH, Mottram JC. Expression of multiple CPB genes encoding cysteine proteases is required for Leishmania mexicana virulence in vivo. Infect Immun 2003; 71(6):3190-3195.

39. Lima AK, Elias CG, Souza JE, Santos AL, Dutra PM. Dissimilar peptidase production by avirulent and virulent promastigotes of Leishmania braziliensis: inference on the parasite proliferation and interaction with macrophages. Parasitology 2009; 136(10):1179-1191. 
40. Rebello KM, Britto C, Pereira BA, Pita-Pereira $\mathrm{D}$, Moraes MO, Ferreira $\mathrm{AB}$, et al. Leishmania (Viannia) braziliensis: influence of successive in vitro cultivation on the expression of promastigote proteinases. Exp Parasitol 2010; 126(4):570-576.

41. Gerbaba TK, Gedamu L. Cathepsin B gene disruption induced Leishmania donovani proteome remodeling implies cathepsin B role in secretome regulation. PLoS One 2013; 8(11):e79951.

42. Casgrain PA, Martel C, McMaster WR, Mottram JC, Olivier M, Descoteaux A. Cysteine peptidase B regulates Leishmania mexicana virulence through the modulation of gp63 expression. PLoS Pathog 2016; 12(5):e1005658.

43. Marín-Villa M, Vargas-Inchaustegui DA, Chaves SP, Tempone AJ, Dutra JM, Soares MJ, et al. The C-terminus extension of Leishmania pifanoi amastigote-specific cysteine proteinase Lpcys2: a putative function in macrophage infection. Mol Biochem Parasitol 2008; 162(1):52-59.

44. Somanna A, Mundodi V, Gedamu L. Functional analysis of cathepsin B-like cysteine proteases from Leishmania donovani complex: evidence for the activation of latent transforming growth factor beta. J Biol Chem 2002; 277(28):25305-25312.

45. Denise H, Poot J, Jiménez M, Ambit A, Herrmann DC, Vermeulen AN, et al. Studies on the CPA cysteine peptidase in the Leishmania infantum genome strain JPCM5. BMC Mol Biol 2006; 7:42.

46. Kuru T, Jirata D, Genetu A, Barr S, Mengistu Y, Aseffa $\mathrm{A}$, et al. Leishmania aethiopica: identification and characterization of cathepsin L-like cysteine protease genes. Exp Parasitol 2007; 115(3):283290.

47. Maekawa $Y$, Himeno $K$, Ishikawa $H$, Hisaeda $H$, Sakai T, Dainichi $\mathrm{T}$, et al. Switch of $\mathrm{CD}^{+} \mathrm{T}$-cell differentiation from Th2 to Th1 by treatment with cathepsin B-inhibitor in experimental leishmaniasis. J Immunol 1998; 161:2120-2127.

48. Zhang T, Maekawa Y, Sakai T, Nakano Y, Ishii K, Hisaeda $\mathrm{H}$, et al.. Treatment with cathepsin $\mathrm{L}$ inhibitor potentiates Th2-type immune response in Leishmania major-infected BALB/c mice. Int Immunol 2001; 13(8):975-982.

49. Rafati S, Nakhaee A, Taheri T, Ghashghaii A, Salmanian $\mathrm{AH}$, Jimenez $\mathrm{M}$, et al. Expression of cysteine proteinase type I and II of Leishmania infantum and their recognition by sera during canine and human visceral leishmaniasis. Exp Parasitol 2003; 103(3-4):143-151.

50. Cameron P, McGachy A, Anderson M, Paul A, Coombs $\mathrm{GH}$, Mottram JC, et al. Inhibition of lipopolysaccharideinduced macrophage IL-12 production by Leishmania mexicana amastigotes: the role of cysteine peptidases and the NF-kappa B signaling pathway. J Immunol 2004; 173(5):3297-3304.

51. Svensjö E, Batista PR, Brodskyn CI, Silva R, Lima AP, Schmitz V, et al. Interplay between parasite cysteine proteases and the host kinin system modulates microvascular leakage and macrophage infection by promastigotes of the Leishmania donovani complex. Microbes Infect 2006; 8(1):206-220.

52. Abu-Dayyeh I, Hassani K, Westra ER, Mottram JC, Olivier M. Comparative study of the ability of Leishmania mexicana promastigotes and amastigotes to alter macrophage signaling and functions. Infect Immun 2010; 78(6):2438-2445.

53. Alves CR, Corte-Real S, Bourguignon SC, Chaves CS, Saraiva EM. Leishmania amazonensis: early proteinase activities during promastigoteamastigote differentiation in vitro. Exp Parasitol 2005; $109(1): 38-48$.

54. Anderson CF, Mendez S, Sacks DL. Non-healing infection despite Th1 polarization produced by a strain of Leishmania major in C57BL/6 mice. J Immunol 2005; 174:2934-2941.

55. Rafati S, Zahedifard F, Azari MK, Taslimi Y, Taheri T. Leishmania infantum: prime boost vaccination with C-terminus extension of cysteine proteinase type I displays both type 1 and 2 immune signatures in BALB/c mice. Exp Parasitol 2008; 118(3):393-401.

56. Pereira BAS, Alves CR. Immunological characteristics of experimental murine infection with Leishmania (Leishmania) amazonensis. Vet Parasitol 2008; 158: 239-255.

57. Pereira BA, Silva FS, Rebello KM, Marín-Villa $\mathrm{M}$, Traub-Cseko YM, Andrade $\mathrm{TC}$, et al. In silico predicted epitopes from the COOH-terminus extension of cysteine proteinase $\mathrm{B}$ inducing distinct immune responses during Leishmania (Leishmania) amazonensis experimental murine infection. BMC Immunol 2011; 12:44.

58. Pereira BA, Britto C, Alves CR. Expression of infection-related genes in parasites and host during murine experimental infection with Leishmania (Leishmania) amazonensis. Microb Pathog 2012; 52(2):101-108.

59. Williams RA, Tetley L, Mottram JC, Coombs GH. Cysteine peptidases CPA and CPB are vital for autophagy and differentiation in Leishmania mexicana. Mol Microbiol 2006; 61(3):655-374.

60. Reece SE, Pollitt LC, Colegrave N, Gardner A. The meaning of death: evolution and ecology of apoptosis in protozoan parasites. PLoS Pathog 2011; 7(12): e1002320.

61. El-Fadili AK, Zangger H, Desponds C, Gonzalez IJ, Zalila $\mathrm{H}$, Schaff $\mathrm{C}$, et al. Cathepsin B-like and cell death in the unicellular human pathogen Leishmania. Cell Death Dis 2010; 1:e71.

62. Quispe Tintaya KW, Ying X, Dedet JP, Rijal S, De Bolle X, Dujardin JC. Antigen genes for molecular epidemiology of leishmaniasis: polymorphism of cysteine proteinase B and surface metalloprotease glycoprotein 63 in the Leishmania donovani complex. J Infect Dis 2004; 189(6):1035-1043.

63. Laurent $T$, Van der Auwera G, Hide M, Mertens P, Quispe-Tintaya W, Deborggraeve S, et al. Identification of Old World Leishmania spp. by specific polymerase chain reaction amplification of cysteine proteinase $B$ genes and rapid dipstick 
detection. Diagn Microbiol Infect Dis 2009; 63(2):173-181.

64. Bhattarai NR, Dujardin JC, Rijal S, De Doncker S, Boelaert M, Van der Auwera G. Development and evaluation of different PCR-based typing methods for discrimination of Leishmania donovani isolates from Nepal. Parasitology 2010; 137(6):947-957.

65. Kuru T, Janusz N, Gadisa E, Gedamu L, Aseffa A. Leishmania aethiopica: development of specific and sensitive PCR diagnostic test. Exp Parasitol 2011; 128(4):391-395.

66. Chaouch M, Fathallah-Mili A, Driss M, Lahmadi R, Ayari C, Guizani I, et al. Identification of Tunisian Leishmania spp. by PCR amplification of cysteine proteinase $\mathrm{B}$ (CPB) genes and phylogenetic analysis. Acta Trop 2013a; 125(3):357-365.

67. Chaouch M, Mhadhbi M, Adams ER, Schoone GJ, LimamS, GharbiZ, etal. Developmentandevaluation of a loop-mediated isothermal amplification assay for rapid detection of Leishmania infantum in canine leishmaniasis based on cysteine protease B genes. Vet Parasitol 2013b; 198(1-2):78-84.

68. da Costa Pinheiro PH, de Souza Dias S, Eulálio KD, Mendonça IL, Katz S, Barbiéri CL. Recombinant cysteine proteinase from Leishmania (Leishmania) chagasi implicated in human and dog T-cell responses. Infect Immun 2005; 73(6):3787-3789.

69. de Souza Dias S, da Costa Pinheiro PH, Katz S, dos Santos MR, Barbiéri CL. A recombinant cysteine proteinase from Leishmania (Leishmania) chagasi suitable for serodiagnosis of American visceral leishmaniasis. Am J Trop Med Hyg 2005; 72(2):126-132.

70. Pinheiro PH, Pinheiro AN, Ferreira JH, Costa FA, Katz S, Barbiéri CL. A recombinant cysteine proteinase from Leishmania (Leishmania) chagasi as an antigen for delayed-type hypersensitivity assays and serodiagnosis of canine visceral leishmaniasis. Vet Parasitol 2009; 162(1-2):32-39.

71. Ferreira JH, Gentil LG, Dias SS, Fedeli CE, Katz $\mathrm{S}$, Barbiéri CL. Immunization with the cysteine proteinase Ldccys1 gene from Leishmania (Leishmania) chagasi and the recombinant Ldccys1 protein elicits protective immune responses in a murine model of visceral leishmaniasis. Vaccine 2008; 26(5):677-685.

72. Pollock KG, McNeil KS, Mottram JC, Lyons RE, Brewer JM, Scott P, et al. The Leishmania mexicana cysteine protease, CPB2.8, induces potent Th2 responses. J Immunol 2003; 170(4):1746-1753.

73. Saravia NG, Escorcia B, Osorio Y, Valderrama $\mathrm{L}$, Brooks D, Arteaga L, et al. Pathogenicity and protective immunogenicity of cysteine proteinasedeficient mutants of Leishmania mexicana in nonmurine models. Vaccine 2006; 24(19):4247-4259.

74. Kumar R, Goto Y, Gidwani K, Cowgill KD, Sundar $\mathrm{S}$, Reed SG. Evaluation of ex vivo human immune response against candidate antigens for a visceral leishmaniasis vaccine. Am J Trop Med Hyg 2010; 82(5):808-813.
75. Rafati S, Nakhaee A, Taheri T, Taslimi Y, Darabi $\mathrm{H}$, Eravani $\mathrm{D}$, et al. Protective vaccination against experimental canine visceral leishmaniasis using a combination of DNA and protein immunization with cysteine proteinases type I and II of $L$. infantum. Vaccine. 2005; 23(28):3716-3725.

76. Saljoughian N, Zahedifard F, Doroud D, Doustdari F, Vasei M, Papadopoulou B, et al. Cationic solid-lipid nanoparticles are as efficient as electroporation in DNA vaccination against visceral leishmaniasis in mice. Parasite Immunol 2013; 35(12):397-408.

77. Noormehr H, Zavaran Hosseini A, Soudi S, Beyzay F. Enhancement of Th1 immune response against Leishmania cysteine peptidase A, B by PLGA nanoparticle. Int Immunopharmacol 2018; 59:97105.

78. Shahbazi M, Zahedifard F, Taheri T, Taslimi Y, Jamshidi S, Shirian S, et al. Evaluation of live recombinant nonpathogenic Leishmania tarentolae expressing cysteine proteinase and A2 genes as a candidate vaccine against experimental canine visceral keishmaniasis. PLoS One 2019; 14(7): e0218050.

79. Khoshgoo N, Zahedifard F, Azizi H, Taslimi Y, Alonso MJ, Rafati S. Cysteine proteinase type III is protective against Leishmania infantum infection in BALB/c mice and highly antigenic in visceral leishmaniasis individuals. Vaccine 2008; 26(46):5822-5829.

80. Dikhit MR, Amit A, Singh AK, Kumar A, Mansuri R, Sinha $S$, et al. Vaccine potential of HLA-A2 epitopes from Leishmania cysteine protease type III (CPC). Parasite Immunol 2017; 39(9): 12 pages.

81. d'Avila-Levy CM, Marinho FA, Santos LO, Martins JLM, Santos ALS, Branquinha MH. Anti-leishmanial activity of MDL28170 a potent calpain inhibitor. Int J Antimicrob Agents 2006; 28: 138-142.

82. Dey R, Bhattacharya J, Datta SC. Calcium-dependent proteolytic activity of a cysteine protease caldonopain is detected during Leishmania infection. Mol Cell Biochem 2006; 281(1-2):27-33.

83. Salotra P, Duncan RC, Singh R, Raju B V S, Sreenivas $G$, Nakhasi HL. Upregulation of surface proteins in Leishmania donovani isolated from patients of post kala-azar dermal leishmaniasis. Microbes Infect 2006;8:637-644.

84. Vergnes B, Gourbal B, Gorard I, Sundar S, Drummelsmith J, Ouellette M. A proteomics screen implicates HSP83 and a small kinetoplastid calpain-related protein in drug resistance in Leishmania donovani clinical field isolates by modulating drug-induced programmed cell death. Mol Cell Proteomics 2007; 6:88-101.

85. Tiwary P, Kumar D, Sundar S. Identification and functional validation of a biomarker for the diagnosis of miltefosine relapse during visceral leishmaniasis. Am J Trop Med Hyg 2018; 98(2):492-496.

86. Das M, Mukherjee SB, Shaha C. Hydrogen peroxide induces apoptosis-like death in Leishmania 
donovani promastigotes. J Cell Sci 2001; 114(13):2461-2469.

87. Arnoult D, Akarid K, Grodet A, Petit PX, Estaquier J, Ameisen JC. On the evolution of programmed cell death: apoptosis of the unicellular eukaryote Leishmania major involves cysteine proteinase activation and mitochondrion permeabilization. Cell Death Differ 2002; 9(1):65-81.

88. González IJ, Desponds C, Schaff C, Mottram JC, Fasel N. Leishmania major metacaspase can replace yeast metacaspase in programmed cell death and has arginine-specific cysteine peptidase activity. Int J Parasitol 2007; 37(2):161-172.

89. Ambit A, Fasel $\mathrm{N}$, Coombs GH, Mottram JC. An essential role for the Leishmania major metacaspase in cell cycle progression. Cell Death Differ 2008; 15(1):113-122.

90. Zalila H, González IJ, El-Fadili AK, Delgado MB, Desponds C, Schaff C, et al. Processing of metacaspase into a cytoplasmic catalytic domain mediating cell death in Leishmania major. Mol Microbiol 2011; 79(1):222-239.

91. Lee N, Gannavaram S, Selvapandiyan A, Debrabant A. Characterization of metacaspases with trypsinlike activity and their putative role in programmed cell death in the protozoan parasite Leishmania. Eukaryot Cell 2007; 6(10):1745-1757.

92. Khademvatan S, Gharavi MJ, Saki J. Miltefosine induces metacaspase and PARP genes expression in Leishmania infantum. Braz J Infect Dis 2011; 15(5):442-448.

93. Raina P, Kaur S. Knockdown of LdMC1 and HSP70 by antisense oligonucleotides causes cell-cycle defects and programmed cell death in Leishmania donovani. Mol Cell Biochem 2012; 359(1-2):135-149.

94. Castanys-Muñoz E, Brown E, Coombs GH, Mottram JC. Leishmania mexicana metacaspase is a negative regulator of amastigote proliferation in mammalian cells. Cell Death Dis 2012; 3:e385.

95. Williams RA, Mottram JC, Coombs GH. Distinct roles in autophagy and importance in infectivity of the two ATG4 cysteine peptidases of Leishmania major. J Biol Chem 2013; 288(5):3678-3690.

96. Azevedo CS, Guido BC, Pereira JL, Nolasco DO, Corrêa R, Magalhães KG, et al.. Revealing a novel Otubain-like enzyme from Leishmania infantum with deubiquitinating activity toward K48-linked substrate. Front Chem 2017; 5:13.

97. Husnjak K, Dikic I. Ubiquitin-binding proteins: decoders of ubiquitin-mediated cellular functions. Annu Rev Biochem 2012; 81, 291-322.

98. Paladi Cde S, Pimentel IA, Katz S, Cunha RL, Judice WA, Caires AC, Barbiéri CL. In vitro and in vivo activity of a palladacycle complex on Leishmania (Leishmania) amazonensis. PLoS Negl Trop Dis 2012; 6(5): e1626.

99. Salerno Pimentel IA, Paladi Cde S, Katz S, de Souza Júdice WA, Cunha RL, Barbiéri CL. In vitro and in vivo activity of an organic tellurium compound on Leishmania chagasi. PLoS One 2012; 7(11): e48780.
100. Quilles JC Jr, Tezuka DY, Lopes CD, Ribeiro FL, Laughton CA, de Albuquerque S, et al. Dipeptidyl nitrile derivatives have cytostatic effects against Leishmania spp. promastigotes. Exp Parasitol 2019 May;200:84-91.

101.Ponte-Sucre A, Vicik R, Schultheis M, Schirmeister T, Moll H. Aziridine-2,3-dicarboxylates, peptidomimetic cysteine protease inhibitors with anti-leishmanial activity. Antimicrob Agents Chemother 2006; 50(7):2439-2447.

102. Schurigt U, Schad C, Glowa C, Baum U, Thomale $\mathrm{K}$, Schnitzer JK, et al. Aziridine-2,3-dicarboxylatebased cysteine cathepsin inhibitors induce cell death in Leishmania major associated with accumulation of debris in autophagy-related lysosome-like vacuoles. Antimicrob Agents Chemother 2010; 54(12):5028-5041.

103. Schad C, Baum U, Frank B, Dietzel U, Mattern F, Gomes C, et al. Development of a new antileishmanial aziridine-2,3-dicarboxylate-based inhibitor with high selectivity for parasite cysteine proteases. Antimicrob Agents Chemother 2015; 60(2):797-805.

104. Gontijo VS, Espuri PF, Alves RB, de Camargos LF, Santos FV, de Souza Judice WA, et al. Leishmanicidal, anti-proteolytic, and mutagenic evaluation of alkyltriazoles and alkyl-phosphocholines. Eur J Med Chem 2015; 101:24-33.

105. Fey P, Chartomatsidou R, Kiefer W, Mottram JC, Kersten C, Schirmeister T. New aziridine-based inhibitors of cathepsin L-like cysteine proteases with selectivity for the Leishmania cysteine protease LmCPB2.8. Eur J Med Chem 2018; 156:587-597.

106. de Almeida L, Alves KF, Maciel-Rezende CM, Jesus Lde O, Pires FR, Junior CV, et al.. Benzophenone derivatives as cysteine protease inhibitors and biological activity against Leishmania (L.) amazonensis amastigotes. Biomed Pharmacother 2015; 75:93-99.

107. Scala A, Rescifina A, Micale N, Piperno A, Schirmeister T, Maes L et al. Ensemble-based ADME-Tox profiling and virtual screening for the discovery of new inhibitors of the Leishmania mexicana cysteine protease CPB2.8DCTE. Chem Biol Drug Des 2018; 91(2):597-604.

108. De Luca L, Ferro S, Buemi MR, Monforte AM, Gitto $\mathrm{R}$, Schirmeister T, et al. Discovery of benzimidazolebased Leishmania mexicana cysteine protease CPB2.8 $\triangle$ CTE inhibitors as potential therapeutics for keishmaniasis. Chem Biol Drug Des 2018; 92(3):1585-1596.

109. Schröder J, Noack S, Marhöfer RJ, Mottram JC, Coombs $\mathrm{GH}$, Selzer PM. Identification of semicarbazones, thiosemicarbazones and triazine nitriles as inhibitors of Leishmania mexicana cysteine protease CPB. PLoS One 2013; 8(10):e77460.

110. Gomes MN, Alcântara LM, Neves BJ, Melo-Filho CC, Freitas-Junior LH, Moraes CB, et al. Computer-aided discovery of two novel chalcone-like compounds 
active and selective against Leishmania infantum. Bioorg Med Chem Lett 2017; 27(11):2459-2464.

111. Besteiro S, Coombs GH, Mottram JC. A potential role for ICP, a leishmanial inhibitor of cysteine peptidases, in the interaction between host and parasite. Mol Microbiol 2004; 54(5): 1224-1236.

112. Smith BO, Picken NC, Westrop GD, Bromek K, Mottram JC, Coombs GH. The structure of Leishmania mexicana ICP provides evidence for convergent evolution of cysteine peptidase inhibitors. J Biol Chem 2006; 281(9):5821-5828.

113. Bryson K, Besteiro S, McGachy HA, Coombs GH, Mottram JC, Alexander J. Overexpression of the natural inhibitor of cysteine peptidases in Leishmania mexicana leads to reduced virulence and a Th1 response. Infect Immun 2009; 77(7):2971-2978.

114. Jecna L, Svarovska A, Besteiro S, Mottram JC, Coombs GH, Volf P. Inhibitor of cysteine peptidase does not influence the development of Leishmania mexicana in Lutzomyia longipalpis. J Med Entomol 2009; 46(3):605-609.

115. Murta AC, Persechini PM, Padron Tde S, de Souza W, Guimarães JA, Scharfstein J. Structural and functional identification of GP57/51 antigen of Trypanosoma cruzi as a cysteine proteinase. Mol Biochem Parasitol 1990; 43(1):27-38.

116. Lima AP, Scharfstein J, Storer AC, Ménard R. Temperature-dependent substrate inhibition of the cysteine proteinase (GP57/51) from Trypanosoma cruzi. Mol Biochem Parasitol 1992; 56(2): 335-338.

117. Campetella O, Henriksson J, Aslund L, Frasch AC, Pettersson U, Cazzulo JJ. The major cysteine proteinase (cruzipain) from Trypanosoma cruzi is encoded by multiple polymorphic tandemly organized genes located on different chromosomes. Mol Biochem Parasitol. 1992; 50(2):225-234.

118. Lima AP, Tessier DC, Thomas DY, Scharfstein J, Storer AC, Vernet T. Identification of new cysteine protease gene isoforms in Trypanosoma cruzi. Mol Biochem Parasitol 1994; 67(2): 333-338.

119. McGrath ME, Eakin AE, Engel JC, McKerrow JH, Craik CS, Fletterick RJ. The crystal structure of cruzain: a therapeutic target for Chagas' disease. J Mol Biol 1995; 247(2):251-259.

120. Cunha-Silva NL, Atella GC, Porto-Carreiro IA, Morgado-Diaz JA, Pereira MG, De Souza W. Isolation and characterization of a reservosome fraction from Trypanosoma cruzi . FEMS Microbiol Lett 2002; 214:7-12.

121. Duschak VG, Ciaccio M, Nassert JR, Basombrio MA. Enzymatic activity, protein expression, and gene sequence of cruzipain in virulent and attenuated Trypanosoma cruzi strains. J Parasitol 2001; 87(5):1016-1022.

122. Porto-Carreiro I, Attias M, Miranda K, De Souza W, Cunha-e-Silva NL. Trypanosoma cruzi epimastigote endocytic pathway: cargo enters the cytostome and passes through an early endosomal network before storage in reservosomes. Eur J Cell Biol 2000; 79: 858-869.

123. Batista CM, Medeiros LC, Eger I, Soares MJ. mAb CZP-315.D9: an anti-recombinant cruzipain monoclonal antibody that specifically labels the reservosomes of Trypanosoma cruzi epimastigotes. Biomed Res Int 2014; 2014:714749.

124. Batista CM, Kessler RL, Eger I, Soares MJ. Trypanosoma cruzi intracellular amastigotes isolated by nitrogen decompression are capable of endocytosis and cargo storage in reservosomes. PLoS One 2015; 10(6):e0130165.

125. Lima L, Ortiz PA, da Silva FM, Alves JM, Serrano MG, Cortez AP, et al. Repertoire, genealogy and genomic organization of cruzipain and homologous genes in Trypanosoma cruzi, T. cruzi-like and other trypanosome species. PLoS One 2012;7(6):e38385.

126. Scharfstein J, Schmitz V, Morandi V, Capella MM, Lima AP, Morrot A, et al. Host cell invasion by Trypanosoma cruzi is potentiated by activation of bradykinin $\mathrm{B}(2)$ receptors. J Exp Med 2000; 192(9):1289-1300.

127. Scharfstein J. Parasite cysteine proteinase interactions with alpha 2-macroglobulin or kininogens: differential pathways modulating inflammation and innate immunity in infection by pathogenic trypanosomatids. Immunobiology 2006; 211(1-2):117-125.

128. Maeda FY, Cortez C, Izidoro MA, Juliano L, Yoshida N. Fibronectin-degrading activity of Trypanosoma cruzi cysteine proteinase plays a role in host cell invasion. Infect Immun 2014; 82(12):5166-74.

129. Ferrão PM, d'Avila-Levy CM, Araujo-Jorge TC, Degrave WM, Gonçalves Ada S, Garzoni LR, et al. Cruzipain activates latent TGF- $\beta$ from host cells during T. cruzi invasion. PLoS One 2015; 10(5):e0124832.

130. Aoki MP, Guinazu NL, Pellegrini AV, Gotoh T, Masih DT, Gea S. Cruzipain, a major Trypanosoma cruzi antigen, promotes arginase- 2 expression and survival of neonatal mouse cardiomyocytes. Am J Physiol Cell Physiol 2004; 286:C206-C212.

131. Aoki MP, Cano RC, Pellegrini AV, Tanos T, Guiñazú $\mathrm{NL}$, Coso OA, et al. Different signaling pathways are involved in cardiomyocyte survival induced by a Trypanosoma cruzi glycoprotein. Microbes Infect 2006; 8(7):1723-1731.

132. Ponce NE, Carrera-Silva EA, Pellegrini AV, Cazorla SI, Malchiodi EL, Lima AP, et al. Trypanosoma cruzi, the causative agent of Chagas disease, modulates interleukin-6-induced STAT3 phosphorylation via gp130 cleavage in different host cells. BiochimBiophysActa 2013; 1832(3):485-494.

133. San Francisco J, Barría I, Gutiérrez B, Neira I, Muñoz C, Sagua H, et al. Decreased cruzipain and gp85/transsialidase family protein expression contributes to loss of Trypanosoma cruzi trypomastigote virulence. Microbes Infect 2017; 19(1):55-61.

134. Uehara LA, Moreira OC, Oliveira AC, Azambuja P, Lima AP, Britto C, et al. Cruzipain promotes 
Trypanosoma cruzi adhesion to Rhodnius prolixus midgut. PLoS Negl Trop Dis 2012; 6(12):e1958.

135. Giordanengo L, Maldonado C, Rivarola HW, Iosa D, Girones N, Fresno M, Gea S. Induction of antibodies reactive to cardiac myosin and development of heart alterations in cruzipain-immunized mice and their offspring. Eur J Immunol 2000; 30(11):3181-3189.

136. Stempin C, Giordanengo L, Gea S, Cerbán F. Alternative activation and increase of Trypanosoma cruzi survival in murine macrophages stimulated by cruzipain, a parasite antigen. J Leukoc Biol 2002; 72(4):727-734.

137. Doyle PS, Zhou YM, Hsieh I, Greenbaum DC, McKerrow JH, Engel JC. The Trypanosoma cruzi protease cruzain mediates immune evasion. PLoS Pathog 2011; 7(9):e1002139.

138. Acosta DM, Arnaiz MR, Esteva MI, Barboza M, Stivale D, Orlando UD, et al. Sulfates are maintargets of immuneresponses to cruzipain and are involved in heartdamage in BALB/cimmunizedmice. Int Immunol 2008; 20(4):461-470.

139. Ferrero MR, Heins AM, Soprano LL, Acosta DM, Esteva MI, Jacobs T, et al. Involvement of sulfates from cruzipain, a major antigen of Trypanosoma cruzi, in the interaction with immunomodulatory molecule Siglec-E. Med Microbiol Immunol 2016; 205(1):21-35.

140. Guiñazú N, Carrera-Silva EA, Becerra MC, Pellegrini A, Albesa I, Gea S. Induction of NADPH oxidase activity and reactive oxygen species production by a single Trypanosoma cruzi antigen. Int J Parasitol 2010; 40(13):1531-1538.

141. Costales J, Rowland EC. A role for protease activity and host-cell permeability during the process of Trypanosoma cruzi egress from infected cells. J Parasitol 2007; 93(6):1350-1359.

142. Miao Q, Santamaria C, Bailey D, Genest J, Ward BJ, Ndao M. Apolipoprotein A-I truncations in Chagas disease are caused by cruzipain, the major cysteine protease of Trypanosoma cruzi. Am J Pathol 2014; 184(4):976-984.

143. Fampa P, Lisboa CV, Jansen AM, Santos AL, Ramirez MI. Protease expression analysis in recently field-isolated strains of Trypanosoma cruzi: a heterogeneous profile of cysteine protease activities between TC I and TC II major phylogenetic groups. Parasitology 2008; 135(9):1093-1100.

144. Fampa P, Santos AL, Ramirez MI. Trypanosoma cruzi: ubiquity expression of surface cruzipain molecules in TCI and TCII field isolates. Parasitol Res 2010; 107(2):443-447.

145. Gomes SA, Misael D, Silva BA, Feder D, Silva CS, Gonçalves TC, et al. Major cysteine protease (cruzipain) in Z3 sylvatic isolates of Trypanosoma cruzi from Rio de Janeiro, Brazil. Parasitol Res 2009;105(3):743-749.

146. Cazorla SI, Frank FM, Becker PD, Corral RS, Guzmán CA, Malchiodi EL. Prime-boost immunization with cruzipain co-administered with MALP-2 triggers a protective immune response able to decrease parasite burden and tissue injury in an experimental Trypanosoma cruzi infection model. Vaccine 2008; 26(16):1999-2009.

147. Pellegrini A, Carrera-Silva EA, Arocena A, Cano RC, Aoki MP, Gea S. Trypanosoma cruzi antigen immunization induces a higher $B$ cell survival in BALB/c mice, a susceptible strain, compared to $\mathrm{C} 57 \mathrm{BL} / 6 \mathrm{~B}$ lymphocytes, a resistant strain to cardiac autoimmunity. Med Microbiol Immuno. 2011; 200(4):209-218.

148.Cerny N, Sánchez Alberti A, Bivona AE, De Marzi MC, Frank FM, Cazorla SI, et al. Co-administration of cruzipain and GM-CSF DNAs, a new immunotherapeutic vaccine against Trypanosoma cruzi infection. Hum Vaccin Immunother 2016; 12(2):438-450.

149. Giese V, Dallagiovanna B, Marchini FK, Pavoni DP, Krieger MA, Goldenberg S. Trypanosoma cruzi: a stage-specific calpain-like protein is induced after various kinds of stress. Mem Inst Oswaldo Cruz 2008; 103: 598-601.

150. Sangenito LS, Ennes-Vidal V, Marinho FA, Da Mota FF, Santos AL, D'Avila-Levy CM, et al. Arrested growth of Trypanosoma cruzi by the calpain inhibitor MDL28170 and detection of calpain homologues in epimastigote forms. Parasitology 2009; 136(4):433-441.

151. Andrade HM, Murta S M F, Chapeaurouge A, Perales J, Nirdé P, Romanha A. Proteomic analysis of Trypanosoma cruzi resistance to benznidazole. J Proteome Res 2008;7:357-2367.

152. Ennes-Vidal V, Menna-Barreto RF, Santos AL, Branquinha $\mathrm{MH}$, d'Avila-Levy CM. Effects of the calpain inhibitor MDL28170 on the clinically relevant forms of Trypanosoma cruzi in vitro. Antimicrob Chemother 2010; 65(7):1395-1398.

153.Ennes-Vidal V, Menna-Barreto RFS, Santos ALS, Bran-quinha MH, d'Avila-Levy CM. MDL28170, a calpain inhibitor, affects Trypanosoma cruzi metacyclogenesis ultrastructure and attachment to Rhodnius prolixus midgut. PLoS One 2011; 6:e18371.

154. El-Sayed NM, Myler PJ, Bartholomeu DC, Nilsson D, Aggarwal G, Tran AN, et al. The genome sequence of Trypanosoma cruzi, etiologic agent of Chagas disease. Science 2005; 309: 409-415.

155. Kosec G, Alvarez VE, Agüero F, Sánchez D, Dolinar M, Turk B, Turk V, et al. Metacaspases of Trypanosoma cruzi: possible candidates for programmed cell death mediators. Mol Biochem Parasitol 2006; 145(1):18-28.

156. Jimenez V, Paredes R, Sosa MA, Galanti N. Natural programmed cell death in T. cruzi epimastigotes maintained in axenic cultures. J Cell Biochem 2008; 105(3):688-698.

157. de Castro E, Reus TL, de Aguiar AM, Ávila AR, de Arruda Campos Brasil de Souza T. Procaspaseactivating compound-1 induces apoptosis in Trypanosoma cruzi. Apoptosis 2017; 22(12):15641577. 
158. Duschak VG, Barboza M, García GA, Lammel EM, Couto AS, Isola EL. Novel cysteine proteinase in Trypanosoma cruzi metacyclogenesis. Parasitology 2006; 132(3):345-355.

159. Alvarez VE, Kosec G, Sant Anna C, Turk V, Cazzulo JJ, Turk B. Blocking autophagy to prevent parasite differentiation: a possible new strategy for fighting parasitic infections? Autophagy 2008; 4(3):361-363.

160. Franke de Cazzulo BM, Martínez J, North MJ, Coombs GH, Cazzulo JJ. Effects of proteinase inhibitors on the growth and differentiation of Trypanosoma cruzi. FEMS Microbiol Lett 1994; 124(1):81-86.

161.Venturini G, Salvati L, Muolo M, Colasanti M, Gradoni L, Ascenzi P. Nitric oxide inhibits cruzipain, the major papain-like cysteine proteinase from Trypanosoma cruzi. Biochem Biophys Res Commun 2000; 270(2):437-341.

162. Abaza SM. Expression of cysteine proteinases and cystatins in parasites and use of cysteine proteinase inhibitors in parasitic diseases. Part III: Protozoa (2): Plasmodium spp. PUJ 2019; 12(2): 72-93.

163. Méndez-Lucio O, Romo-Mancillas A, MedinaFranco JL, Castillo R. Computational study on the inhibition mechanism of cruzain by nitrilecontaining molecules. J Mol Graph Model 2012; 35:28-35.

164. Ndao M, Beaulieu C, Black WC, Isabel E, VasquezCamargo F, Nath-Chowdhury $\mathrm{M}$, et al. Reversible cysteine protease inhibitors show promise for a Chagas disease cure. Antimicrob Agents Chemother 2014; 58(2):1167-1178.

165. Avelar LA, Camilo CD, de Albuquerque S, Fernandes WB, Gonçalez C, Kenny PW, et al. Molecular design, synthesis and trypanocidal activity of dipeptidyl nitriles as cruzain inhibitors.PLoSNegl Trop Dis 2015; 9(7):e0003916.

166. Chiyanzu I, Hansell E, Gut J, Rosenthal PJ, McKerrow $\mathrm{JH}$, Chibale K. Synthesis and evaluation of isatins and thiosemicarbazone derivatives against cruzain, falcipain-2 and rhodesain. Bioorg Med Chem Lett 2003; 13(20):3527-3530.

167.Du X, Guo C, Hansell E, Doyle PS, Caffrey CR, Holler TP, et al. Synthesis and structure-activity relationship study of potent trypanocidal thio semicarbazone inhibitors of the trypanosomal cysteine protease cruzain. J Med Chem 2002; 45(13):2695-2707.

168. Choe Y, Brinen LS, Price MS, Engel JC, Lange M, Grisostomi C, et al. Development of alpha-ketobased inhibitors of cruzain, a cysteine protease implicated in Chagas disease. Bioorg Med Chem 2005; 13(6):2141-2156.

169. Trossini GH, Guido RV, Oliva G, Ferreira EI, Andricopulo AD. Quantitative structure-activity relationships for a series of inhibitors of cruzain from Trypanosoma cruzi: molecular modeling, CoMFA and CoMSIA studies. J Mol Graph Model 2009; 28(1):3-11.
170. Magalhaes Moreira DR, de Oliveira AD, Teixeira de Moraes Gomes PA, de Simone CA, Villela FS, Ferreira RS, et al. Conformational restriction of aryl thiosemicarbazones produces potent and selective anti-Trypanosoma cruzi compounds which induce apoptotic parasite death. Eur J Med Chem 2014; 75:467-478.

171. de Moraes Gomes PA, de Oliveira Barbosa M, Farias Santiago E, de Oliveira Cardoso MV, Capistrano Costa NT, Hernandes MZ, et al. New 1,3-thiazole derivatives and their biological and ultrastructural effects on Trypanosoma cruzi. Eur J Med Chem 2016; 121:387-398.

172. Vital DG, Damasceno FS, Rapado LN, Silber AM, Vilella FS, Ferreira RS, et al. Application of bioisosterism in design of the semicarbazone derivatives as cruzain inhibitors: a theoretical and experimental study. J Biomol Struct Dyn 2017; 35(6):1244-1259.

173. Engel JC, Doyle PS, Hsieh I, McKerrow JH. Cysteine protease inhibitors cure an experimental Trypanosoma cruzi infection. J Exp Med 1998; 188(4):725-734.

174. Engel JC, Torres C, Hsieh I, Doyle PS, McKerrow JH. Upregulation of the secretory pathway in cysteine protease inhibitor-resistant Trypanosoma cruzi. J Cell Sci 2000; 113(8): 1345-1354.

175. Barr SC, Warner KL, Kornreic BG, Piscitelli J, Wolfe A, Benet L, et al. A cysteine protease inhibitor protects dogs from cardiac damage during infection by Trypanosoma cruzi. Antimicrob Agents Chemother 2005; 49(12):5160-5161.

176. McKerrow JH, Doyle PS, Engel JC, Podust LM, Robertson SA, Ferreira R, et al. Two approaches to discovering and developing new drugs for Chagas disease. Mem Inst Oswaldo Cruz 2009; 104(Suppl. 1): $263-269$

177. Martinez-Mayorga K, Byler KG, Ramirez-Hernandez AI, Terrazas-Alvares DE. Cruzain inhibitors: efforts made, current leads and a structural outlook of new hits. Drug Discov Today 2015; 20(7):890-898.

178. Brak K, Doyle PS, McKerrow JH, Ellman JA. Identification of a new class of nonpeptidic inhibitors of cruzain. J Am Chem Soc 2008; 130(20):6404-6410.

179. Brak K, Kerr ID, Barrett KT, Fuchi N, Debnath M, Ang $\mathrm{K}$, et al. Non peptidic tetrafluorophenoxymethyl ketone cruzain inhibitors as promising new leads for Chagas disease chemotherapy. J Med Chem 2010; 53(4):1763-1773.

180. Romeiro NC, Aguirre G, Hernández P, González M, Cerecetto H, Aldana I, et al. Synthesis, trypanocidal activity and docking studies of novel quinoxaline$\mathrm{N}$-acylhydrazones, designed as cruzain inhibitors candidates. Bioorg Med Chem 2009; 17(2):641-652.

181. Luci D, Lea W, Ferreira R, Shoichet B, Simeonov A, Rodriguez A, et al. Reversible and non-covalent benzimidazole-based in vivo lead for Chagas disease. A website 15 Apr. 2011, Last update on 28 Feb. 2013 www.ncbi.nlm.nih.gov/books/NBK133417/. 
182. Jones BD, Tochowicz A, Tang Y, Cameron MD, McCall LI, Hirata K, et al. Synthesis and evaluation of oxyguanidine analogues of the cysteine protease inhibitor WRR-483 against cruzain. ACS Med Chem Lett 2016;7(1):77-82.

183. Sbaraglini MLBellera CL, Fraccaroli L, Larocca L, Carrillo C, Talevi A, et al. Novel cruzipain inhibitors for the chemotherapy of chronic Chagas disease. Int J Antimicrob Agents 2016; 48(1):91-95.

184. de Souza AS, de Oliveira MT, Andricopulo AD. Development of a pharmacophore for cruzain using oxadiazoles as virtual molecular probes: quantitative structure-activity relationship studies. J Comput Aided Mol Des 2017; 31(9):801816.

185. Serrano M, Gonzalez V, Ray S, Chavez MD, Narayan M. Identification of structure-stabilizing interactions in enzymes: a novel mechanism to impact enzyme activity. Cell Biochem Biophys 2018; 76(1-2):59-71.

186. Rampogu S, Lee G, Baek A, Son M, Park C, Zeb A, et al. Discovery of non-peptidic compounds against Chagas disease applying pharmacophore guided molecular modelling approaches. Molecules 2018; 23(12).

187. Santos CC, Sant'anna C, Terres A, Cunha-eSilva NL, Scharfstein J, de A Lima AP. Chagasin, the endogenous cysteine-protease inhibitor of Trypanosoma cruzi, modulates parasite differentiation and invasion of mammalian cells. J Cell Sci 2005; 118(5): 901-915.

188. Buarque DS, Spindola LM, Martins RM, Braz GR, Tanaka AS. Tigutcystatin, a cysteine protease inhibitor from Triatoma infestans midgut expressed in response to Trypanosoma cruzi. Biochem Biophys Res Commun 2011; 413(2):241247.

189. Mbawa ZR, Gumm ID, Shaw E, Lonsdale-Eccles JD. Characterisation of a cysteine protease from bloodstream forms of Trypanosoma congolense. Eur J Biochem 1992; 204(1):371-379.

190. Caffrey CR, Hansell E, Lucas KD, Brinen LS, Alvarez Hernandez A, Cheng J, et al. Active site mapping, biochemical properties and subcellular localization of rhodesain, the major cysteine protease of Trypanosoma brucei rhodesiense. Mol Biochem Parasitol 2001; 118(1):61-73.

191. Caffrey CR, Scory S, Steverding D. Cysteine proteinases of trypanosome parasites: novel targets for chemotherapy. Curr Drug Targets 2000; 1(2):155-162.

192. Lalmanach G, Boulangé A, Serveau C, Lecaille F, Scharfstein J, Gauthier F et al. Congopain from Trypanosoma congolense: drug target and vaccine candidate. Biol Chem. 2002; 383(5): 739-749.

193. Mackey ZB, O'Brien TC, Greenbaum DC, Blank $\mathrm{RB}$, McKerrow JH. A cathepsin B-like protease is required for host protein degradation in Trypanosoma brucei. J Biol Chem 2004; 279(46):48426-48433.
194.Steverding D, Sexton DW, Wang X, Gehrke SS, Wagner GK, Caffrey CR. Trypanosoma brucei: chemical evidence that cathepsin $\mathrm{L}$ is essential for survival and a relevant drug target. Int J Parasitol 2012;42(5):481-488.

195. O'Brien TC, Mackey ZB, Fetter RD, Choe Y, O'Donoghue AJ, Zhou M, et al. A parasite cysteine protease is key to host protein degradation and iron acquisition. J Biol Chem 2008; 283(43):2893428943.

196. Uzureau P, Uzureau S, Lecordier L, Fontaine $\mathrm{F}$, Tebabi $\mathrm{P}$, Homble $\mathrm{F}$, et al. Mechanism of Trypanosoma brucei gambiense resistance to human serum. Nature 2013; 501(7467):430-434.

197. Alsford S, Currier RB, Guerra-Assuncao JA, Clark TG, Horn D. Cathepsin-L can resist lysis by human serum in Trypanosoma brucei brucei. PLoS Pathog 2014; 10(5):e1004130.

198. Nikolskaia OV, de A Lima AP, Kim YV, LonsdaleEccles JD, Fukuma T, Scharfstein J, et al. Blood-brain barrier traversal by African trypanosomes requires calcium signaling induced by parasite cysteine protease. J Clin Invest 2006; 116(10):2739-2747.

199. Ortiz PA, Maia da Silva F, Cortez AP, Lima L, Campaner M, Pral EM, et al. Genes of cathepsin L-like proteases in Trypanosoma rangeli isolates: markers for diagnosis, genotyping and phylogenetic relationships. Acta Trop 2009; 112(3):249-259.

200. Cortez AP, Rodrigues AC, Garcia HA, Neves L, Batista JS, Bengaly Z, et al. Cathepsin L-like genes of Trypanosoma vivax from Africa and South America--characterization, relationships and diagnostic implications. Mol Cell Probes 2009; 23(1):44-51.

201. Rodrigues AC, Garcia HA, Ortiz PA, Cortez AP, Martinkovic F, Paiva F, et a. Cysteine proteases of Trypanosoma (Megatrypanum) theileri: cathepsin L-like gene sequences as targets for phylogenetic analysis, genotyping diagnosis. Parasitol Int 2010; 59(3):318-325.

202. Garcia HA, Kamyingkird K, Rodrigues AC, Jittapalapong S, Teixeira MM, Desquesnes M. High genetic diversity in field isolates of Trypanosoma theileri assessed by analysis of cathepsin L-like sequences disclosed multiple and new genotypes infecting cattle in Thailand. Vet Parasitol 2011; 180(3-4):363-367.

203. Rodrigues AC, Ortiz PA, Costa-Martins AG, Neves L, Garcia HA, Alves JM, et al. Congopain genes diverged to become specific to Savannah, Forest and Kilifi subgroups of Trypanosoma congolense, and are valuable for diagnosis, genotyping and phylogenetic inferences. Infect Genet Evol 2014;23:20-31.

204. El-Sayed NM, Hedge P, Quackenbush J, Melville SE, Donelson JE. The African trypanosome genome. Int J Parasitol 2000; 30: 329-345.

205. Hertz-Fowler C, Ersfeld K, Gull K. CAP5: a lifecycle-regulated cytoskeleton-associated protein is a member of a novel family of calpain-related 
proteins in Trypanosoma brucei. Mol Biochem Parasitol 2001; 116:25-34.

206. Olego-Fernandez S, Vaughan S, Shaw MK, Gull K, Ginger ML. Cell morphogenesis of Trypanosoma brucei requires the paralogous, differentially expressed calpain-related proteins CAP5.5 and CAP5.5V. Protist 2009; 160(4):576-590.

207. Liu W, Apagyi K, McLeavy L, Ersfeld K. Expression and cellular localization of calpain-like proteins in Trypanosoma brucei. Mol Biochem Parasitol 2010; 169(1):20-26.

208. Hope R, Egarmina K, Voloshin K, Waldman BenAsher H, Carmi S, Eliaz D, et al. Transcriptome and proteome analyses and the role of atypical calpain protein and autophagy in the spliced leader silencing pathway in Trypanosoma brucei. Mol Microbiol 2016;102(1):1-21.

209. Mottram JC, Helms MJ, Coombs GH, Sajid M. Clan CD cysteine peptidases of parasitic protozoa. Trends Parasitol 2003; 19, 182-187.

210. Helms MJ, Ambit A, Appleton P, Tetley L, Coombs GH, Mottram JC. Bloodstream form Trypanosoma brucei depend upon multiple metacaspases associated with RAB11-positive endosomes. J Cell Sci 2006; 119(6):1105-1117.

211. Moss CX, Westrop GD, Juliano L, Coombs GH, Mottram JC. Metacaspase 2 of Trypanosoma brucei is a calcium-dependent cysteine peptidase active without processing. FEBS Lett 2007; 581(29): 5635-5639.

212. McLuskey K, Rudolf J, Proto WR, Isaacs NW, Coombs GH, Moss CX, et al. Crystal structure of a Trypanosoma brucei metacaspase. Proc Natl Acad Sci USA 2012; 109(19):7469-7474.

213. Gilio JM, Marcondes MF, Ferrari D, Juliano MA, Juliano L, Oliveira V, et al. Processing of metacaspase 2 from Trypanosoma brucei (TbMCA2) broadens its substrate specificity. Biochim Biophys Acta Proteins Proteom 2017; 1865(4):388-394.

214. Eyssen LE, Coetzer THT. Expression, purification and characterization of Trypanosoma congolense metacaspase 5 (TcoMCA5): a potential drug target for animal African trypanosomiasis. Protein Expr Purif 2019; 164:105465.

215. Proto WR, Castanys-Munoz E, Black A, Tetley L, Moss CX, Juliano L, et al. Trypanosoma brucei metacaspase 4 is a pseudopeptidase and a virulence factor. J Biol Chem. 2011; 286(46): 39914-3925.
216. Mott BT, Ferreira RS, Simeonov A, Jadhav A, Ang $\mathrm{KK}$, Leister $\mathrm{W}$ et al. Identification and optimization of inhibitors of trypanosomal cysteine proteases: cruzain, rhodesain, and TbCatB. J Med Chem 2010; 53(1):52-60.

217. Mallari JP, Zhu F, Lemoff A, Kaiser M, Lu M, Brun $\mathrm{R}$, et al. Optimization of purine-nitrile TbcatB inhibitors for use in vivo and evaluation of efficacy in murine models. Bioorg Med Chem 2010; 18(23): 8302-8309.

218. Ehmke V, Winkler E, Banner DW, Haap W, Schweizer WB, Rottmann $\mathrm{M}$, et al. Optimization of triazine nitriles as rhodesain inhibitors: structure-activity relationships, bioisostericimidazopyridine nitriles, and X-ray crystal structure analysis with human cathepsin L. Chem Med Chem 2013; 8(6):967-975.

219. Yang PY, Wang M, Li L, Wu H, He CY, Yao SQ.Design, synthesis and biological evaluation of potent azadipeptide nitrile inhibitors and activity-based probes as promising anti-Trypanosoma brucei agents. Chemistry 2012; 18(21):6528-6541.

220.Schirmeister T, Schmitz J, Jung S, Schmenger T, Krauth-Siegel RL, Gütschow M. Evaluation of dipeptide nitriles as inhibitors of rhodesain, a major cysteine protease of Trypanosoma brucei. Bioorg Med Chem Lett 2017; 27(1):45-50.

221. Unciti-Broceta JD, Maceira J, Morales S, GarcíaPérez A, Muñóz-Torres ME, Garcia-Salcedo JA. Nicotinamide inhibits the lysosomal cathepsin B-like protease and kills African trypanosomes. J Biol Chem 2013; 288(15):10548-10557.

222. Chen YT, Lira R, Hansell E, McKerrow JH, Roush WR. Synthesis of macrocyclic trypanosomal cysteine protease inhibitors. Bioorg Med Chem Lett 2008; 18(22):5860-5863.

223. Bryant C, Kerr ID, Debnath M, Ang KK, Ratnam J, Ferreira RS, et al. Novel non-peptidic vinyl sulfones targeting the S2 and S3 subsites of parasite cysteine proteases. Bioorg Med Chem Lett 2009; 19(21):6218-6221.

224. Steverding D. Evaluation of trypanocidal activity of combinations of anti-sleeping sickness drugs with cysteine protease inhibitors. Exp Parasitol 2015; 151-152: 28-33.

225. Santos CC, Coombs GH, Lima ACA, Mottram JC. Role of the Trypanosoma brucei natural cysteine peptidase inhibitor ICP in differentiation and virulence. Mol Microbiol 2007; 66(4): 991-1002. 